\title{
Measurement and Evaluation of Lighting/HVAC Interaction
}

Stephen d. Treado, Mechanical Engineer

John W. Bean, Mathematician

U.S. DEPARTMENT OF COMMERCE National Institute of Standards and Technology Lighting Croup Building Environment Division Building and Fire Research Laboratory Gaithersburg, MD 20899 
NATIONAL MJSTHTUTE OF STANDARDS \& TECHNOLOGY

Research Information Center

Gaithersburg, MD 20899 
Measurement and

Evaluation of

Lighting/HVAC

Interaction

Stephen J. Treado, Mechanical Engineer

John W. Bean,

Mathematician

U.S. DEPARTMENT OF COMMERCE National Institute of Standards and Technology

Uighting Group

Buildine Environment Division

Building and Fire Research Laboratory

Gaithersburg, MD 20899

May 1991

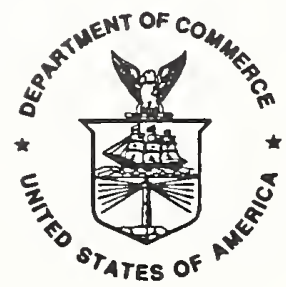

US. DEPARTMENT OF COMMERCE Robort A. Mosbacher, Secretary

MATIONN INSTITUTE OF STANDARDS AND TECHNOLOGY

John $w$. Lyone, Director 



\section{ABSTRACT}

The interaction of building lighting and HVAC systems and the effects on cooling load and lighting system performance are being evaluated using a full-scale test facility at the National Institute of Standards and Technology (NIST). The test facility and measurement methodology are described, along with sample test data and performance evaluation results. The implications of measurement uncertainty on results are discussed.

Keywords: airflow, cooling, energy, lighting, load calculation, ventilation 
The authors would like to acknowledge the support of the Department of Energy, Office of Building Technology, and their project managers, Mr. Mark Bailey and Dr. Lee Anderson. The cooperation of EPRI and Ross and Baruzzini is also appreciated.

\section{Disclaimer}

Any equipment or other references to particular products found in this report are for informational purposes only and do not constitute an endorsement. 
Table of Contents

1. Introduction .. . . . . . . . . . . . . . . . . . 1

2. Background . . . . . . . . . . . . . . . . . . 2

3. Purpose of Test Facility . . . . . . . . . . . . . . . . 4

4. Test Facility Design and Operation . . . . . . . . . . . . 6

5. Results of Performance Evaluatin and Calibration . . . . . 8

5.1. Measurement of Cooling Load due to Lighting . . . . . . 9

5.2. Temperature Measurements . . . . . . . . . . . . . 14

5.3. Surface Heat Flow Sensors. . . . . . . . . . . . 16

6. Conclusions . . . . . . . . . . . . . . . . . . 16

7. References . . . . . . . . . . . . . . . . . 17 


$$
\text { List of Tables }
$$

Table 1

Table 2

Table 3
Temperature Comparisons

East Wall Temperatures

19

Heat Flow Sensor Readings 


\section{List of Figures}

Figure 1 Energy distribution fractions from lighting systems

Figure 2 Typical profile of cooling load due to lighting for cyclic 22 daily operation of the lights

Figure 3 Temperature dependence of a typical fluorescent lamp

Figure 4 Cut-away schematic of the NIST Lighting/HVAC Interaction

Test Facility

Figure 5 Transient test showing cooling load response due to switching of the lighting system

Figure 6 Measured cooling load, lighting power and airflow rate

for a transient lights-on test

Figure 7 Measured room and plenum air temperatures for a transient 27 lights-on test

Figure 8 Measured floor and ceiling slab surface temperatures

for a transient lights-on test

Figure 9 Measured room and plenum wall temperatures for a transient lights-on test

Figure 10 Measured minimum lamp wall temperature for a transient lights-on test

Figure 11 Measured cooling load with experimental curve fit

Figure 12 Thermopile readings during a transient test, including wall, slab and air thermopiles

Figure 13 Wall thermopile readings during transient test

Figure 14 Cooling load profile with no excess heat gains or heat sources

Figure 15 Cooling load profile with constant auxiliary heat source

Figure 16 Cooling load profile with variable auxiliary heat source

Figure 17 Measured lighting power and cooling load for transient test showing zero and full scale offsets

Figure 18 Measured cooling lod adjusted for excess heat gains

Figure 19 Wall and slab heat flow sensor readings 
Figure 20 Wall heat flow sensor reading 40

Figure 21 Slab heat flow sensor readings 41

Figure 22 Excess heat gains based on heat flow sensor readings 42

Figure 23 Measured cooling load adjusted using heat flow sensors 43 vs. equilibrium calibration

Figure 24 Cooling load profile with 3 percent offset 44

Figure 25 Normalized cooling load profile with 3 percent offset 45 
Lighting in commercial buildings is the single largest user of electric energy, typically ranging from $25 \%$ to $50 \%$ of total building electrical energy requirements. In $1980,2.8\left(10^{15}\right)$ Btu of energy was used for lighting for a total cost of over 40 billion dollars annually [1]. An overall increase in lighting efficiency of one percent would produce a savings of 400 million dollars a year.

The performance of the dominant commercial light source, the fluorescent lamp, is strongly dependent on thermal conditions, with both lamp light output and power consumption varying with minimum lamp wall temperature as much as 208 under typically encountered conditions. Proper control of room thermal conditions can ensure that the lamps are operating at their most efficient level.

In addition to the electrical energy purchased and used for lighting itself, heat dissipated from the lighting system adds to a building's cooling load in summer and decreases the heating requirements in winter. Controlling peak cooling loads in summer is of particular interest to electric utilities, which are under pressure reduce summer peaks to control peak electric power demands. Due to finite electric power generation resources, steady electric power demands make the most efficient use of electric power generation facilities. The capital cost of expansion of generating capacity has, in turn, led to greater costs to the user in the form of demand charges and ratchet clauses. A demand charge usually takes the form of a higher unit cost for electrical power during periods of heavy system - wide use. Demand charges frequently are assessed from late morning through early evening.

A ratchet clause ties the unit cost for electric power for the entire year to the maximum electric power demand over a specified interval. The interval might be several hours or longer during periods of heavy use. With this sort of clause, even a single day of excessive electrical demand could result in significant increases in the total annual cost of lighting energy. Higher peak cooling loads also require larger equipment sizes to maintain comfort conditions, resulting in higher first costs.

A research effort was established to determine energy transfer from lighting systems to building spaces and to evaluate the performance of lighting and HVAC equipment as influenced by typical operating conditions and equipment configurations. The program is co-funded by the U.S. Department of Energy and the Electric Power Research Institute. The objective of the research effort is to develop procedures to promote the design of efficient lighting and HVAC systems, leading to energy and cost savings. A combination of detailed full-scale measurements of lighting and HVAC performance and related computer simulations forms the basis of the approach to these issues. This paper will focus on the measurement of lighting and HVAC system performance. More detailed results are contained in [2] and [3]. 
A full-scale test facility was constructed to simulate an office space. The test facility was extensively instrumented to allow the measurement of lighting levels, electrical power consumption, heat transfer, and temperatures. Various lighting and HVAC system designs have been tested, along with other room-related parameters. The parameters that have been evaluated include:

- luminaire type

- lamp type

- number of lamps per luminaire

- room air temperature

- airflow rate, constant or variable

- return airflow path

- carpet

- furnishings

- internal electric loads

A finite difference computer model of the test facility has been developed and is being used to extend the measurement results. This model will also form the basis of a subroutine that can be incorporated in larger building energy analysis computers.

This report describes the results of a detailed evaluation and calibration of the NIST Lighting and HVAC Interaction test facility. The purpose of the evaluation was to examine and document the performance of the test facility including the measurement systems and procedures. Specific questions regarding the determination of cooling load profiles due to lighting, temperature distribution measurements, and control system operation are addressed. Measurement uncertainties and their effects on results and conclusions are described.

\section{Background}

There are two major issues associated with the interaction of 1 ighting and HVAC systems in buildings. One issue is the efficiency of the lighting system. Energy for lighting and the number of luminaires required to provide the desired light levels will be minimized if the luminaires are operated at their most efficient temperature. The total heat gain to the building space from the luminaires would also be minimized at this condition, meaning minimum cooling loads from lighting.

Figure 1 shows the energy distribution components from a lighting fixture, or luminaire. All of the electrical energy input to the luminaire is dissipated into the building space as visible light, convection, conduction, or thermal radiation. Some of the energy goes into the room and some into the plenum, if there is one present. The net effect of all of these modes of heat transfer determine the luminaire's heat balance and equilibrium temperature.

The second issue relates to the peak cooling loads due to lighting. When a lighting system is switched on, all of the electrical power input does not show up as cooling load immediately because of heat storage in 
building components, plenum air (if any), and the luminaires themselves. of course, once the lights are turned off, the stored heat will be dissipated to the room air and eventually appear as cooling load. The result is the same total cooling load but a lower peak load. Thus, peak cooling loads due to lighting can be controlled by channeling some of the energy dissipated by the luminaire into components such as floor and ceiling slabs, walls, and furnishings, thereby redistributing the cooling load due to lighting over a longer period of time.

Figure 2 shows a typical profile of cooling load due to lighting for cyclic daily operation of the lights. The cooling load is plotted relative to the lighting power. Maximum cooling load due to lighting occurs just before the lights are switched off. The difference between the peak cooling load due to lighting and the lighting input power is the peak load reduction.

Luminaire temperatures are determined by the total room thermal environment, including air and surface temperatures, airflow rates, and supply and return air configurations. Maximum light output and powerconsumption occur when a lamp's cold spot is approximately $104^{\circ} \mathrm{F}$, although not necessarily occur at exactly the same temperature, as shown in Figure 3. Maximum lamp luninous efficacy also occurs near $104^{\circ} \mathrm{F}$, usually coincident with the point of maximum light output. The exact temperature dependence of different lamps varies somewhat, but all display the same general behavior as shown in Figure 3 [4].

Other factors also influence fluorescent lamp performance, including lamp length and diameter, lamp loading, and argon pressure. However, these other factors are usually fixed for a particular lamp installation and are not dependent on the thermal conditions. On the other hand, the thermal conditions to which a fluorescent luminaire, that is, the lamp and fixture combination, is exposed can significantly alter lamp temperature and, thus, lamp performance. These thermal conditions include air temperatures, airflow conditions near the luminaire, and thermal radiation exchange with surrounding surfaces. It is important to note that the thermal environment is somewhat under the control of the building designer, allowing it to be tailored to promote efficient luminaire operating conditions, while maintaining adequate comfort conditions. 
The test facility was designed to emulate a full-size office space with typical lighting and HVAC system configurations. The intent was to strike a balance between an actual building, which presents insurmountable measurement obstacles, and a strictly laboratory test apparatus, which lacks realism and typical construction materials and practices. The test facility consists of a fully instrumented test room, which functions as a calorimeter, surrounded by controlled guard air spaces, which simulate adjacent rooms. Data collection and control are accomplished by a computer-based system. The details of the test facility and instrumentation system have been previously published [3].

The design of the test facility was established to meet the following objectives of the research project:

1. Evaluate cooling loads due to lighting, both under steadystate and transient operation.

2. Evaluate lighting efficiency as influenced by lighting and HVAC system design and operation.

3. Develop methods for predicting and controlling peak cooling loads due to lighting.

4. Develop methods for optimizing lighting system efficiency by identifying and utilizing the interactions between the lighting and HVAC systems.

A full-size test facility was selected for the research project because of the current lack of knowledge regarding energy flows and heat transfer from the lighting system to the building space and HVAC system. Simulation techniques must incorporate many simplifying assumptions, thereby limiting their usefulness and sensitivity to changes in lighting system design. Examples of these assumptions include uniform room and plenum air temperatures, uniform wall and floor temperatures, handbook convection heat transfer coefficients, idealized radiant heat transfer and simplified luminaire modeling. While computer simulations can be useful in many instances, full-scale measurements are needed to validate and calibrate the analytical models, and to establish the reasonableness of their output.

On the other hand, performing full-scale measurements of lighting and HVAC interactions is a formidable task in its own right. Several sources of information are available to help establish the best methods and performance expectations for measuring cooling load due to lighting in a full-size test facility. The original measurements of lighting cooling load were conducted at the National Research Council of Canada [5]. These measurements form the basis for the lighting cooling load factors found in the ASHRAE Handbook of Fundamentals [6]. Other relevant information is contained in two ASTM standards: C236 (Standard Test Method for Steady State Performance of Building Assemblies by Means of a Guarded Hot Box) 
and 6976 (Standard Test Method for Thermal Performance of Building Assemblies by Means of a Calibrated Hot Box). These two ASTM standards are useful because a test facility for evaluating lighting cooling load is essentially a guarded calorimeter being operated in a calibrated mode. That is, the test facility is designed to minimize unwanted heat transfer to the test room (i.e. it is guarded) and the cooling load due to lighting is determined through calibration of the test room.

The NRC test facility, like the NIST test facility, had a duplicate lighting system beneath the floor slab; however, the floor slab was 6 inches thick whereas the NIST facility floor is $21 / 2$ inches thick on a steel deck. The NRC test room had foil-covered foam walls with air circulated on the guard side equal to the room-side wall surface temperature. On the top of the ceiling slab, a pond of water was circulated at a uniform temperature controlled to match the floor temperature in the test room. The entire test room HVAC system was contained within the test room, including the fan, cooling coil and heater. Cooling load due to lighting was determined from a room heat balance accounting for electric power supplied to the fan and heater, and heat extracted by the cooling coil. The residual heat gain or loss from the test room to the surroundings, which manifests itself as a non-zero cooling load with no lights on, was assumed to be constant and was used as the lighting cooling load zero value. The difference between this lighting cooling load baseline value and the measured cooling load at any time during a test was attributed to the lighting cooling load. No attempt was made to account for or adjust the cooling load to match the metered lighting input power at steady-state, lights-on conditions. Thus the lighting cooling load weighting factors were determined strictly through a regression analysis of the shape of the measured transient cooling load profile, which was assumed to be due to lighting system effects only.

ASTM standard C976 outlines a procedure for calibrating a hot box calorimeter through the use of a reference standard. A correction factor is derived based on heat transfer through a known specimen compared to the measured heat transfer. The measured and actual heat transfers will differ due to losses through chamber walls or other paths. The measurement of cooling load due to lighting is analogous except that the metered lighting power input provides two known calibration values: steady-state lights off (zero lighting cooling load), and steady-state lights on (full-metered lighting power). ASTM C976 allows for dynamic testing, but cautions that care must be taken when heat-capacity effects predominate.

The calibration principle, as well as the guarding techniques described in ASTM standard C236, are utilized by the NIST test facility as they were for the NRC test facility. As is described in ASTM C236, the guard air spaces maintain a zero temperature difference across the room walls to minimize unwanted heat flow. ASTM C236 recognizes that small temperature gradients may still exist through the walls, allowing some heat flow, and state that this can be corrected for in calculating test results. In the NIST test facility, the test room walls are constructed of gypsum board 
with an insulated wall cavity, and the guard space air is controlled so that the surfaces of the room walls are maintained at equal temperatures. This allows heat storage in the walls, but no net heat flow through the walls. In a similar manner, the top of the ceiling slab is controlled to match the top of the floor, and the bottom of the floor slab to match the bottom of the ceiling. As is described in ASTM C236, thermopiles are used to measure and control the appropriate surface temperatures. It is further stated that the thermopile junctions may be taped or cemented to the appropriate surfaces, and that the indicated temperature should be within $\pm 0.2 \mathrm{C}$ of the actual temperature. In the NIST test facility, thermopiles are used with 30 pairs of junctions to control the walls, and 36 pairs to control the slabs.

\section{Test Facility Design and Operation}

The test facility is constructed on a slab $30 \mathrm{ft}, 6$ in. by $21 \mathrm{ft}, 4 \mathrm{in}$. within the large NIST environmental chamber. The facility is divided into two sections, a large insulated shell enclosing the test room area and a smaller attached control room for housing instrumentation. The overall height is $20 \mathrm{ft}, 10 \mathrm{l} / 2 \mathrm{in.}$, while the control room ceiling height is 13 ft, $21 / 2$ in. The test room floor slab is elevated to accommodate a lower plenum beneath the floor, and all other room surfaces are adjacent to temperature - controlled guard air spaces. Duplicate lighting and HVAC systems are installed in both the test room plenum and the lower plenum. Figure 4 shows a cut - away schematic view of the test facility. The majority of the ductwork is not shown in this figure.

The test room floor and ceiling slabs are 2 1/2 in. thick concrete built on steel decks supported by a structural steel framework. The test room walls are constructed of gypsum drywall on steel studs. The initial test configuration is four interior walls.

The lighting system locations in the test room and lower plenum are identical. The edges of the floor slabs extend slightly beyond the walls, while the ceiling slab separates the side guard air spaces from the upper guard air space. Small access doors allow entry into the guard air spaces. A large double door opens from the north guard air space. Another door connects the test room/guard air portion of the test facility with steps leading to the floor of the control room.

The operation of the test facility, data collection, and control of measurements is by a personal computer-based data acquisition and control system. The computer collects data and controls the heaters and fan and other measurement parameters under the control of a specialized computer program. A total of 398 parameters are sampled every 12 second or two minutes and recorded at two-minute intervals.

The primary measurement parameters are lighting power, cooling load, return airflow rate, and room temperature. Additional measurements of air and surface temperatures, heat flows, and light levels are intended to 
supply supporting information. Some of the measurements also serve as feedback signals for the control loops, such as the floor and wall thermopiles.

Lighting power is measured using a solid-state transducer with a current output proportional to power consumption. This sensor was calibrated and found to have an uncertainty of less than 0.18 .

The cooling load for the test room is given by:

$$
\begin{aligned}
& \mathrm{Q}=\dot{\mathrm{m} C P} \Delta \mathrm{T}=(\mathrm{AF})(\rho)(\mathrm{CP})\left(\mathrm{T}_{\mathrm{RET}}-\mathrm{T}_{\mathrm{SUP}}\right) \\
& \dot{\mathrm{m}}=\text { mass flow rate of air } \\
& \mathrm{AF}=\text { airflow } \\
& \rho=\text { density of standard air } \\
& \mathrm{CP}_{\mathrm{P}}=\text { specific heat of air } \\
& \mathrm{T}_{\mathrm{RET}}=\text { return air temperature } \\
& \mathrm{T}_{\mathrm{SUP}}=\text { supply air temperature }
\end{aligned}
$$

The test room air temperature for a single sensor is measured with an array of 64 thermocouples, in a four-by-four-by-four grid. The upper 16 thermocouples are in the plenum, while the average of the 48 thermocouples below the suspended ceiling is used as the room temperature control point. Temperature measurement uncertainty for a single sensor is $\pm 0.75^{\circ} \mathrm{F}$. However, software calibration and averaging reduce this to about $\pm 0.25^{\circ} \mathrm{F}$.

As was mentioned above, thermopiles are used extensively for feedback to control the test room's boundary conditions. The most typical boundary condition is to simulate a test room surrounded by similar spaces. Thus, wall temperature conditions would be symmetrical about the center plane of each test room wall, and the surface temperature would remain equal on both sides of the wall. The average temperature difference across each wall is measured using type $\mathrm{T}$ thermopiles with 30 pairs of junctions. The control system attempts to keep the thermopile readings equal to zero by varying the power supplied to each electric duct heater. When the lights are switched on, the interiors of the test room walls begin to heat up, causing an imbalance in surface temperatures across the walls that is sensed by the thermopile, which, in turn, causes the control signal to the appropriate heater to increase. In this manner, heat can be stored in the gypsum board walls, but no net heat flow through the wall will occur. The control of the lower plenum and upper guard air space is also accomplished using thermopiles.

The measurement of cooling load due to lighting has an uncertainty of approximately \pm 48 . This is primarily due to lack of perfect control of the guard air spaces, which potentially allows the test room boundary conditions to deviate from an ideal state. The test room does, however, constitute a real controlled building space, and, as such, the measured cooling loads are representative of those which that in an actual building. 
Both steady-state and transient tests can be run in the test facility. Steady-state tests involve establishing a test configuration and allowing conditions to stabilize. The transient tests involve the response of cooling load due to sudden switching of the lighting system, as shown schematically in Figure 5. Thus, the test facility goes from one steadystate condition, either lights on or off, to the other steady-state condition. Periodic operation of the lighting and/or internal electric equipment is also possible.

The test facility is essentially a guarded calorimeter being operated in a calibrated mode, with test room functioning as a calorimeter. The procedures for operating a guarded calorimeter are detailed in ASTM Standard C-236. Guard air spaces are used to minimize unwanted heat transfer. However, some unwanted heat transfer will occur for large test facilities. Thus, the principles of operating a calibrated hot box, as described in ASTM Standard C-976, are utilized. This involves correcting the measured cooling loads by subtracting any excess heat gains or losses as determined through calibration. The steady-state lights-off and lights-on conditions provide two points to calibrate the cooling load measurement. The metered lighting input power functions as the cooling load reference.

Examples of measurement data are shown in the following series of figures, for a transient lights-on test. Figure 6 shows cooling load, lighting power, and supply-return airflow rate. The test room was initially at equilibrium with the lights off. At time zero, the lighting system was energized and the room cooling load begun to increase. At the same time, the plenum air temperature increases, as shown in Figure 7, while room air tempertaure is held constant. Heat storage in the floor and ceiling slabs causes their temperature to increase, as shown in Figure 8 . Similarly, the plenum wall temperature increases more than the room walls, as shown in Figure 9. The fluorescent lamps heat up very quickly, as shown in Figure 10.

The measured cooling load is fitted with a double exponential curve as shown in Figure 11. The experimental curve is a compact way to represent the measured data and leads to the weighting factors which are used for cooling load calculations [3].

5. Results of Performance Evaluation and Calibration

Throughout the project a number of test facility performance and calibration issues have been addressed. In a large, complex test facility many factors can influence the measured results, including measurement uncertainty, calibration, malfunctions and operating conditions. The performance of the test facility is constantly monitored to enable identification and rectification of any problems. Periodic recalibrations of measurement systems and upgrading of equipment also occur. This section details some of the results from various test facility performance assessments. 


\subsection{Measurement of Cooling Load due to Lighting}

There are two aspects related to the accuracy of the measurement of lighting cooling load. One is the uncertainty associated with the actual cooling load measurement, and the other is whether the cooling load being measured is due to lighting or being influenced by something else, such as heat transfer through the test room envelope. Under steady-state conditions, neither aspect is of concern, since the cooling load due to lighting is equal to the lighting input power, which can be measured with an uncertainty of less than one percent. Otherwise, the uncertainty of the cooling load measurement (i.e. aspect one from above) is less than 4 percent. This uncertainty, however, is primarily systematic throughout a single test, as opposed to random, so it has a minimal effect on the shape of the measured transient cooling load profile. In support of this statement, over 150 transient tests were evaluated to determine the change in excess heat gains between the lights-off and lights-on condition. The average change in excess heat gains (or heat balance) was 2.2 percent, with a statement deviation of 0.049 . Thus, the excess heat gain are nearly constant throughout a transient test. It is only the shape of the transient cooling load profile that affects the resulting weighting factors and cooling load factors. Any constant or proportional cooling load components have no influence. Thus, the major concern is whether the measured cooling load contains transients which are not due to lighting cooling load.

In order to address this issue, we can begin by looking for evidence that other transient cooling loads are occurring. The "real life" nature of the test facility ensures that some unwanted heat transfers are taking place, but the facility is specifically designed to minimize these effects. The best indicators of cooling load measurement performance are the actual cooling load profiles, the control thermopile readings, the surface temperature measurements and the surface heat flow sensor readings.

The control thermopile readings are consistently controlled to zero by the guard air spaces. While this does not completely eliminate all excess heat gain to the test room, it is an indication that the guard air spaces are performing to minimize excess heat transfer. The fact that some heat transfer occurs is a fact of life with a "real" test room with large surface areas, due to real non-uniformities in surface temperatures, thermal bridges and control system operation. Figures 12 and 13 show plots of the thermopile readings during a transient lights on test. Only the supply to return air temperature difference deviates from zero (figure 12), as it should as room cooling load picks up. The guard space thermopiles, which should read zero, do so with average values of less than $0.03^{\circ} \mathrm{F}$. The random fluctuations of the thermopile outputs due to noise and control system operation (figure 13) are small (typically less than $0.25^{\circ} \mathrm{F}$ ), centered about zero. These thermopile results are repeated and consistently every test. 
When the test facility is in operation, in the absence of any auxiliary electric load the only planned heat source to the test room is the lighting system. Thus, when the lights are off the cooling load due to lighting should be zero. However, the measured cooling load for the test room is not identically zero due to unwanted heat transfer through the test room envelope. The guard air spaces are controlled to minimize these excess heat gains (or losses), but the large surface area of the test room $\left(-1000 \mathrm{ft}^{2}\right)^{2}$ and use of actual building materials and construction practices prevents the attainment of a perfect zero cooling load condition.

It is important to distinguish conceptually between cooling load due to lighting and test room cooling load. The test room cooling load is the measured cooling load including heat from the lights and any excess heat gains or losses. The cooling load due to lighting includes only the portion of the room cooling load associated with the heat from the lighting system. There are two natural calibration points for the measurement of cooling load due to lights. Under equilibrium conditions when the lights are off, cooling load due to lights is zero. Similarly, at equilibrium with the lights on, cooling load due to lights is equal to the full lighting power, since all of the energy supplied to the lights is dissipated into the test room. Thus the magnitude of any excess heat gains can be determined under equilibrium conditions by comparing the measured room cooling load to the measured lighting power.

Ideally, the magnitude of the excess heat gains would be small and constant. Small excess heat gains would have a negligible effect on the thermal conditions in the test room. Constant excess heat gains would not affect the transcient cooling loads due to lighting. The basic transient cooling load test conducted in the test facility consists of starting at equilibrium with the lights off, switching the lights on, and waiting until equilibrium conditions are achieved. The shape of the cooling load profile determines the weighting factors which are used to characterize and compute cooling load due to lights for other lighting operation patterns. Only the shape of the cooling load profile influences the resulting weighting factors. Any systematic offset or proportional scale factor (i.e. addition or multiplication by a constant) has no effect on the lighting cooling load profile or the weighting factors. Thus, the important point is whether the excess heat gains contribute a significant transient cooling load with a time constant different from the transient lighting cooling load. Any other excess heat gain pattern is unimportant.

Before presenting measured data to examine the effect of excess heat gains, on test facility performance, a few logical analyses might prove useful for clarifying the situation.

Assume that the test facility was perfectly operated so that the measured cooling load was exactly equal to the cooling load due to lights (i.e. zero excess heat gains). A transient lights-on test would produce a cooling load profile as shown in figure 14. If a small heater, say 15 
watts, were then placed in the test room and the transient lights-on test were repeated, a different cooling load profile would be produced, as shown in figure 15. However, the shape of both cooling load profiles would be identical, as would the resulting weighting factors, and the cooling load due to lights would be the same for both tests.

Now assume that the heater in the room is equipped with a controllable output. At the beginning of the test, the heater dissipates 10 watts into the room and gradually increases to 20 watts by the end of the test. Thus, the measured cooling load would contain a variable excess heat gain component, as shown in figure 16. If the variation in cooling load due to lights (i.e. if the transient time constants) were the same as that of the heater, the measured cooling load profile and weighting factors would be identical to those for the case without a heater. Is it logical to think that the time constant for the excess heat gains is similar to the time constant for the cooling load due to lights? The change in excess heat gains from the lights-off to the lights-on condition is due to the nonuniform heating of room surfaces, particularly the floor and ceiling slabs. When the lights are off, the test room is at a uniform temperature, while when the lights are on, the room is cooler than the plenum. The profile of cooling load due to lights is a function of the heat storage which is occurring as room surfaces heat up. Thus, since both the change in excess heat gains and the lighting cooling load profiles are due to heating of room surfaces, it is likely that both occur at about the same rate. To the extent that the excess heat gain transient does not track the lighting cooling load transient, an uncertainty in the determination of cooling load due to lighting from the measured room cooling load will be present. This uncertainty has been included in the accuracy estimates of 4 percent.

The above issues are illustrated in the following series of figures, for a typical transient lights-on test. Figure 17 shows measured lighting power and room cooling load. The lights were switched on at time zero. Before the lights were turned on, a residual cooling load of about 20 watts was present. This zero offset is due to excess heat gain to the test room. At equilibrium with the lights on, measured room cooling load does not equal lighting power, again due to excess heat gains. This full scale offset is also about 20 watts.

The procedure of attributing the change in test room cooling load to the cooling load due to lighting is exactly identical to substracting the zero offset from the room cooling load profile, and then multiplying the resulting curve by a scaling factor. In practice, it is not necessary to perform these operations, since they have no effect on the shape of the cooling load profile, the exponential regression or the resulting weighting factors. However, these procedures have been done for this test to illustrate the effect of the excess heat gains and to examine the underlying assumptions.

Figure 18 demonstrates what happens to the cooling load profile when it is adjusted as described above. The measured cooling load profile is shifted to start at zero and end equal to the measured lighting power. The two 
cooling load profiles shown in the figure are the room cooling load (upper) and the lighting cooling load (lower). The difference between the curves is the excess heat gains, which have been estimated from the steady state lights-off and lights-on conditions. The negative of the excess heat gains, or the difference between the lighting cooling load and room cooling load, are shown at the bottom of the figure as a nearly horizontal line of about 20 watts. This adjustment factor for excess heat gains is nearly constant, changing with the same time constant as the measured cooling load. The excess heat gains are about 6 percent of the lighting power, and the change in excess heat gains is less than one percent throughout the test.

The magnitude of the excess heat gains are known exactly under equilibrium conditions by comparing the measured room cooling load to the lighting power. However, during transient conditions, excess heat gains can not be determined directly from measurement. However, examination of heat flow sensor readings provides clues regarding the transient excess heat gains, enabling an assessment of whether the transient excess heat gains are "well-behaved" so as to not significantly corrupt the determination of cooling load due to lighting.

One large area heat flow sensor is located at the center of each room surface, including the walls, floor and ceiling slab. All of the sensors are located on the room side, except for the ceiling slab heat flow sensor, which is mounted on top of the slab. This was necessary due to the corrugated steel deck on the bottom of the slab, which would not allow the heat flow sensor to be mounted. This heat flow sensor produces high frequency variations in output as it responds to the operation of the upper guard air space temperature control, and thus is not an accurate indicator of heat flow at the bottom of the ceiling slab, which is considerably smoothed due to the mass of the concrete slab.

The heat flow sensors give a good indication of the excess heat gains through the test room surfaces, but not a perfect quantitative heat balance since they do not cover all of the room surface area. However, they do illuminate the transient behavior of the excess heat gains. When the lights are off, all of the heat flow sensors should read zero, since no heat transfer should occur under equilibrium lights-off conditions. When the lights are turned on, the wall heat flow sensors should show heat flow into the walls as they heat up, gradually returning to zero heat flow under equilibrium lights-on conditions. The floor and ceiling slab heat flows should match as heat is stored in the slabs, and reach a steady nonzero reading under equilibrium lights-on conditions. This is because the plenum is hotter than the room, so heat flows upward through both the floor and ceiling slabs.

These trends are shown in figure 19 for the walls and slab, and figure 20 for the slabs only. In figure 19, with the lights off, a net heat gain of about 0.2 watts $/ \mathrm{m}^{2}$ occurs through the walls (a negative sign indicates heat flow out of the surface). When the lights are switched on, heat flows into the walls, gradually returning to a steady wall heat flow of about 0.2 watts $/ \mathrm{m}^{2}$ into the room. No significant heat flow transients are seen, 
except for the expected heat storage in the walls. The fast transients are due to the sensitivity of the heat flow sensors to local air turbulence and convection effects.

Figure 20 shows the heat flow sensor readings for the slabs. The smoothly varying curve is the floor heat flow sensor, which is on the room side, while the wildly fluctuating curve is the heat flow sensor on top of the ceiling slab. The control of the test facility is intended to match these two heat flows. To the extent that they do not match, excess heat gains occur. Discounting the fast variations in ceiling slab top heat flow, the two curves track reasonably well. The heat flow into the bottom of the ceiling slab will vary much less rapidly than is shown by the heat flow sensor on the top of the ceiling slab due to the damping effect of the slab. The floor slab heat flow tracks the average of the ceiling slab heat flow.

It should be pointed out that the control of the upper guard air space is the most difficult function in the test facility. First, the plenum beneath the ceiling slab heats up non-uniformly due to the lights. Second, no lights are installed in the upper guard air space, so temperature control is dependent on convective heat transfer from the air. Third, the control is based on thermopile readings which are maintaining average surface temperatures for a discrete set of thermopile junction locations. The improvement of the upper guard air space control is under continuing investigation.

If the heat flow sensor readings are taken to be good indicators of excess heat gains, they can be compared to the estimated excess heat gains determined from equilibrium conditions. Also the measured cooling load can be adjusted using the heat flow sensor readings, and compared to the lighting cooling load determined using the excess heat gains estimated from the equilibrium conditions.

Figure 21 shows the excess heat gains determined based on the heat flow sensor readings. These were determined by multiplying each heat flow sensor reading by the appropriate surface area and summing the results. The result is the curve varying between zero and -25 watts. The wide variations in this plot are all due to the heat flow sensor on top of the ceiling slab, as was described above. These variations are not reflected in the measured cooling load, which is also shown in the figure, so their effect should be discounted. What is important is that the excess heat gains indicated by the heat flow sensors are essentially constant. Heat flow into the walls during the first four or five hours of the test is not an excess heat gain, so this portion of the heat flow sensor excess heat gain curve should be ignored. The average magnitude of the heat flow sensor excess heat gain curve is less than the excess heat gains based on equilibrium conditions. However, at equilibrium conditions the excess heat gains are known exactly from calibration, and the heat flow sensor curve is consistently offset by the same amount. This is due to the fact that the heat flow sensors are measuring only the center of each room surface, so do not provide exact heat balance information. The important 
point is that the transient behavior of the excess heat gains as indicated by the heat flow sensors is consistent with the desired "well-behaved" conditions.

Figure 22 shows the measured cooling load adjusted using the heat flow sensor readings versus the equilibrium condition calibration. The two curves are very similar, except for the variations due to the ceiling slab heat flow sensor. Again, since these variations are not seen in the measured cooling load, they are measurement artifacts and should be discounted. Also, the first five hours of the heat flow sensor readings contain wall heat flows which are not excess heat gains. Thus, the cooling loads should not be compared then. The general shape of the two cooling load curves is very similar. When the cooling load profiles are fit with exponential relations, the rapid variations are smoothed out, leaving very similar shapes of the cooling load profiles.

The above analysis supports the use of the measured cooling load profile as representative of the cooling load due to lighting. Control system operation and transient excess heat gains introduce an envelope of measurement uncertainty in the cooling load due to lights. This envelope has a magnitude zero at equilibrium with the lights off, broadens during the transient portion of the cooling load profile, and gradually returns to zero at lights-on equilibrium. The effect of this envelope of uncertainty is demonstrated in figures 23 and 24 . Figure 24 shows a cooling load profile similar to a typical exponential fit to measured data. Also shown is a curve which is 3 percent less, simulating a systematic 3 percent error. While this error band appears to be large, this is misleading. Since the cooling load profile is normalized, the entire curve is scaled, as shown in figure 24. The 3 percent envelope is much less after normalization. Thus, a 3 percent transient uncertainty in the excess heat gains would fall within the envelope defined by the two cooling load profile curves, and the affect would be marginal.

\subsection{Temperature Measurements}

As opposed to temperature difference measurements which are made with multi-junction thermopiles, all temperatures are measured using Type $T$ thermocouples. Sixteen thermocouples (TC's) are read by each of 16 input cards. Each card has its own temperature compensation sensor in an isothermal input terminal block. Like all TC measurement systems, each individual TC generates a small voltage proportional to the difference in temperature between the TC junction and the input terminal. This voltage is converted into a temperature difference through software (polynomial conversion) and added to the temperature of the input terminal, which is assumed to be the same as that measured at the center of the input block. The manufacturer states the following uncertainties:

temperature compensation reference $\pm 0.25^{\circ} \mathrm{C}$ offset between input terminal and reference $\pm 0.25^{\circ} \mathrm{C}$ thermocouple wire accuracy $\pm 0.4^{\circ} \mathrm{C}$ 
Additional uncertainty components are associated with the measurement of the TC voltage and the A to D conversion, but in practice these are small. The thermocouple wire accuracy is primarily systematic for a single manufactured lot of wire. Most, but not all, of the TC wires used in the test facility are from the same lot (all of the thermopile wires are from the same spool).

The temperature compensation turns out to be the primary source of temperature measurement concern, but fortunately it varies systematically in blocks of $16 \mathrm{TC}$ 's (i.e. per each input card).

All of the thermocouple input cards were calibrated for voltage measurement zero and gain. Then, ice baths were used to determine temperature compensation offsets for each input card. A detailed comparison of measured temperatures was performed at steady state with both lights off and lights on. Excellent agreement and uniformity were observed where expected.

Table 1 lists the average measured temperatures for each of the major room components, with the lighting system off and on. These temperatures are listed in degrees $\mathrm{C}$, which is the actual measurement format, and have been adjusted by subtracting the ice point reference offset. Also listed are the changes in temperature from lights off to on. This table demonstrates several things. First, although the room air temperature was set for $23.9^{\circ} \mathrm{C}\left(75^{\circ} \mathrm{F}\right)$, the actual air temperature was controlled to $23.2^{\circ} \mathrm{C}$ $\left(73.8^{\circ} \mathrm{F}\right)$. This is not critical as long as the temperature was held constant throughout the test, which it was, changing by less than $0.02^{\circ} \mathrm{F}$. The ice point offset corrections are being incorporated into the data collection program to eliminate this effect. More importantly, temperatures are very uniform with lights off, and increase properly with the lights on. For example, all of the room wall temperatures increase between 0.400 to $0.48^{\circ} \mathrm{F}$, and the plenum wall temperatures increase between 2.21 to $2.66^{\circ} \mathrm{F}$. The west wall appears to be the warmest, but it has only $3 \mathrm{TC}^{\prime} \mathrm{s}$ in the room and $1 \mathrm{TC}$ in the plenum. One of the west wall TC's was found to be defective, so only two are included in the average. The results are similar for the other temperature measurements. In fact, any apparent unusual temperature variation can be shown to be attributable to the temperature reference offset.

Table 2 shows the changes in east wall surface tempertures from lights off to lights on conditions. Temperatures are very uniform with the lights off, but vary as much as $1^{\circ} \mathrm{F}$ with lights on. This is due to non-uniform thermal conditions when the lights are on.

Since the temperature reference offset is present in the raw temperature data, how can the data be used? Throughout the project we have used software temperature compensation to account for this effect. When the lights are off, the thermocouples are adjusted to a common reference, the room air temperature, and then the changes in temperatures throughout the duration of the test are determined. This allows individual calibration of each thermocouple. The temperature reference hardware calibrations can only be done in blocks of $16 \mathrm{TC}$ 's. 
As was discussed above, large heat flow sensors are mounted at the center of each of the room surfaces, except for the steel deck due to its corrugated nature. These sensors develop a millivolt signal proportional to the heat flow through each sensor into the surface. These heat flow sensors provide two useful pieces of information. First, they give a quantitative estimate of the magnitude of the heat flows into the surfaces during steady state and transient conditions. Second, the shape of the transient heat flow into or out of the surface during a test indicates whether spurious transient heat flows are occurring due to the guard air space control.

Table 3 lists the heat flow sensor readings during steady state lights off and lights on conditions. This table shows that although the thermopile reading is being held at zero for the entire surface, some heat flow is occurring. For the walls, excess heat flow is about 2 or 3 watts for each wall, into the test room, with the lights off or on. This represents about 10 to 12 watts total. The floor slab heat flow sensor, which should be reading zero, shows 20 watts of heat gain to the room with the lights off. With the lights on, the floor heat flow sensor should not read zero, since heat flow is expected to occur from the lower plenum to the test room. However, heat gain through the floor slab should equal heat loss through the ceiling slab. The heat flow sensors indicate 46.6 watts of heat gain through the floor and 16.6 watts heat loss through the ceiling, for a net differential of 30 watts.

These heat flow readings illuminate the source of the cooling load zero and full scale offsets, which would be about 30 watts and 40 watts, respectively based solely on the heat flow sensor readings. The difference in the excess heat gain from lights off to lights on is about 10 watts, or 38 of lighting power. This is consistent with the other evaluations of the excess heat gains.

\section{Conclusions}

The results of the test facility performance evaluations show that the facility is operting similar to an actual building, with many of the real world effects of control systems, materials and non-uniform thermal conditions. These complicate the task of isolating lighting system performance, but are essential to the realistic testing of interactions between the lighting system, room and HVAC system. While control system performance is not perfect, it is representative of actual building conditions. The determination of cooling load due to lighting, does not seem to be compromised by the operation of the test facility, and other measurement parameters, such as temperatures and heat flows, verify proper test facility operation. 
7. References

1. United States Department of Energy, Overview of Building Energy Use and Report of Analysis - 1985, Office of Building and Community Systems, Washington, DC, October, 1985.

2. Treado, S.J., Experimental Plan for Investigation of Lighting and HVAC Interactions, NBSIR 87-3656, National Bureau of Standards, October, 1987.

3. Treado, S.J., Bean, J.W., The Interaction of Lighting, Heating and Cooling Systems in Buildings - Interim Report, NISTIR 88-3860, National Institute of Standards and Technology, September, 1988.

4. IES Lighting Handbook, Reference Edition, Illuminating Engineering Society of North America, 1984.

5. Mitalas, G.P., Cooling Load Caused by Lights, Transactions CSME Vol. 2 , No. 3, 1973-1974.

6. ASHRAE Handbook of Fundamentals, ASHRAE, Atlanta, GA, 1989. 
Table 1 Temperature Comparisons

\begin{tabular}{|c|c|c|c|c|}
\hline Location & Lights off & Lights on & $\begin{array}{l}\text { On }- \\
{ }^{\circ} \mathrm{C}\end{array}$ & Off ${ }^{\circ} \mathrm{F}$ \\
\hline Room Air & $23.21^{\circ} \mathrm{C}$ & $23.20^{\circ} \mathrm{C}$ & -0.01 & -0.02 \\
\hline Plenum Air & 22.96 & 23.87 & 0.91 & 1.64 \\
\hline North Wall & 23.14 & 23.37 & 0.22 & 0.40 \\
\hline North Plenum & 23.09 & 24.32 & 1.23 & 2.21 \\
\hline East Wall & 23.33 & 23.39 & 0.24 & 0.43 \\
\hline East Plenum & 23.09 & 24.43 & 1.34 & 2.42 \\
\hline South Wall & 23.16 & 23.40 & 0.24 & 0.42 \\
\hline South Plenum & 22.97 & 24.23 & 1.26 & 2.27 \\
\hline West Wall & 23.57 & 23.83 & 0.27 & 0.48 \\
\hline West Plenum & 22.96 & 24.44 & 1.48 & 2.66 \\
\hline Floor & 23.48 & 24.09 & 0.61 & 1.11 \\
\hline Ceiling & 23.18 & 24.04 & 0.86 & 1.55 \\
\hline
\end{tabular}




\begin{tabular}{ccccc} 
TC\# & off & On & \multicolumn{2}{c}{ On - Off } \\
Room 17 & $23.12^{\circ} \mathrm{C}$ & $23.46^{\circ} \mathrm{C}$ & 0.34 & 0.61 \\
18 & 22.82 & 23.14 & 0.32 & 0.58 \\
19 & 23.12 & 23.14 & 0.02 & 0.04 \\
22 & 23.12 & 23.76 & 0.64 & 1.15 \\
23 & 23.12 & 23.44 & 0.32 & 0.58 \\
24 & 23.12 & 23.44 & 0.32 & 0.58 \\
25 & 23.12 & 23.46 & 0.34 & 0.61 \\
26 & 23.12 & 23.14 & 0.02 & 0.04 \\
27 & 23.12 & 23.14 & 0.02 & 0.04 \\
30 & 23.12 & 23.12 & 0.34 & 0.61 \\
31 & 23.12 & 23.46 & 0.04 & 0.04
\end{tabular}




\begin{tabular}{lccccc} 
& & \multicolumn{2}{c}{ Lights off } & \multicolumn{2}{c}{ Lights On } \\
Location & Area $\mathrm{m}^{2}$ & $\mathrm{w} / \mathrm{m}^{2}$ & $\mathrm{w}$ & $\mathrm{w} / \mathrm{m}^{2}$ & $\mathrm{w}$ \\
\hline north wall & 13.7 & -0.2278 & -3.12 & -0.2293 & -3.14 \\
east wall & 11.7 & -0.2208 & -2.58 & -0.2688 & -3.14 \\
south wall & 13.7 & -0.1561 & -2.14 & -0.1504 & -2.07 \\
west wall & 11.7 & -0.1791 & -2.10 & -0.1845 & -2.16 \\
floor slab top & 15.6 & -1.3078 & -20.4 & -2.9908 & -46.66 \\
ceiling slab top & 15.6 & -0.07267 & -1.13 & -1.0667 & -16.64
\end{tabular}

Note: Negative sign denotes heat flow out of surface 


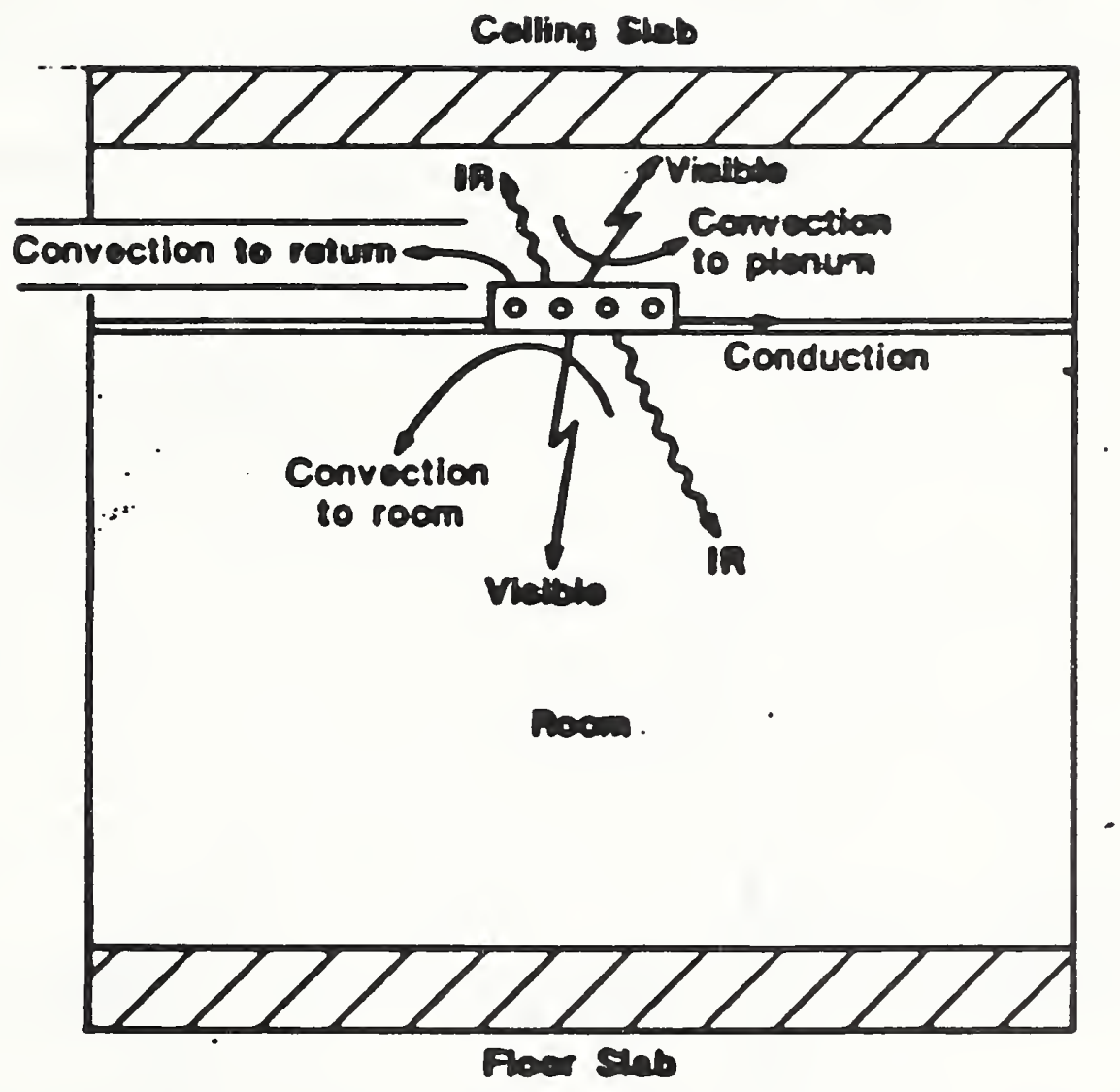

Figure 1. Energy distribution fractions from lighting systems 


\section{COOLING LOAD WITH CYCLIC LIGHTING}

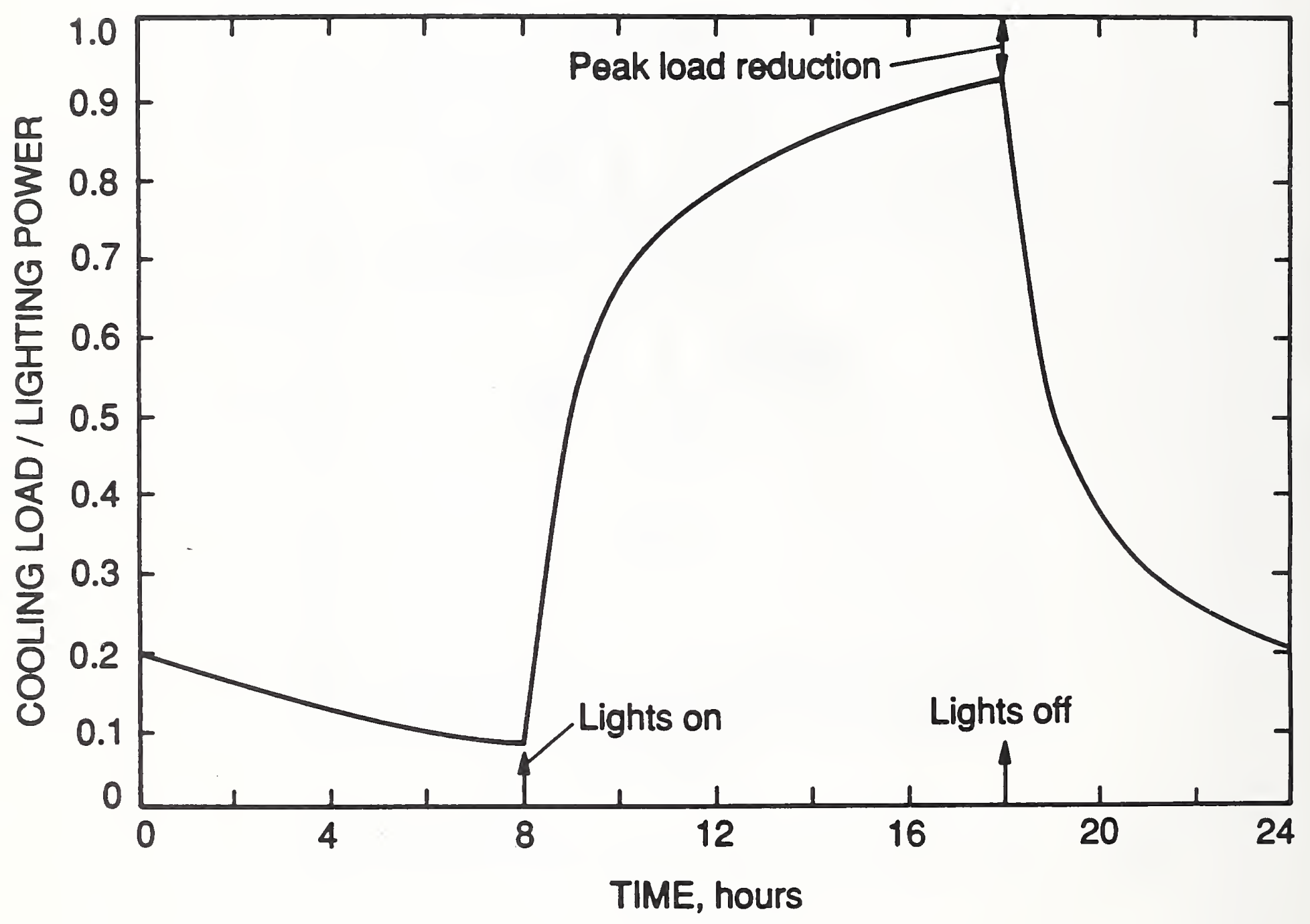

Figure 2. Typical profile of cooling load due to lighting for cyclic dally operation of the lights 


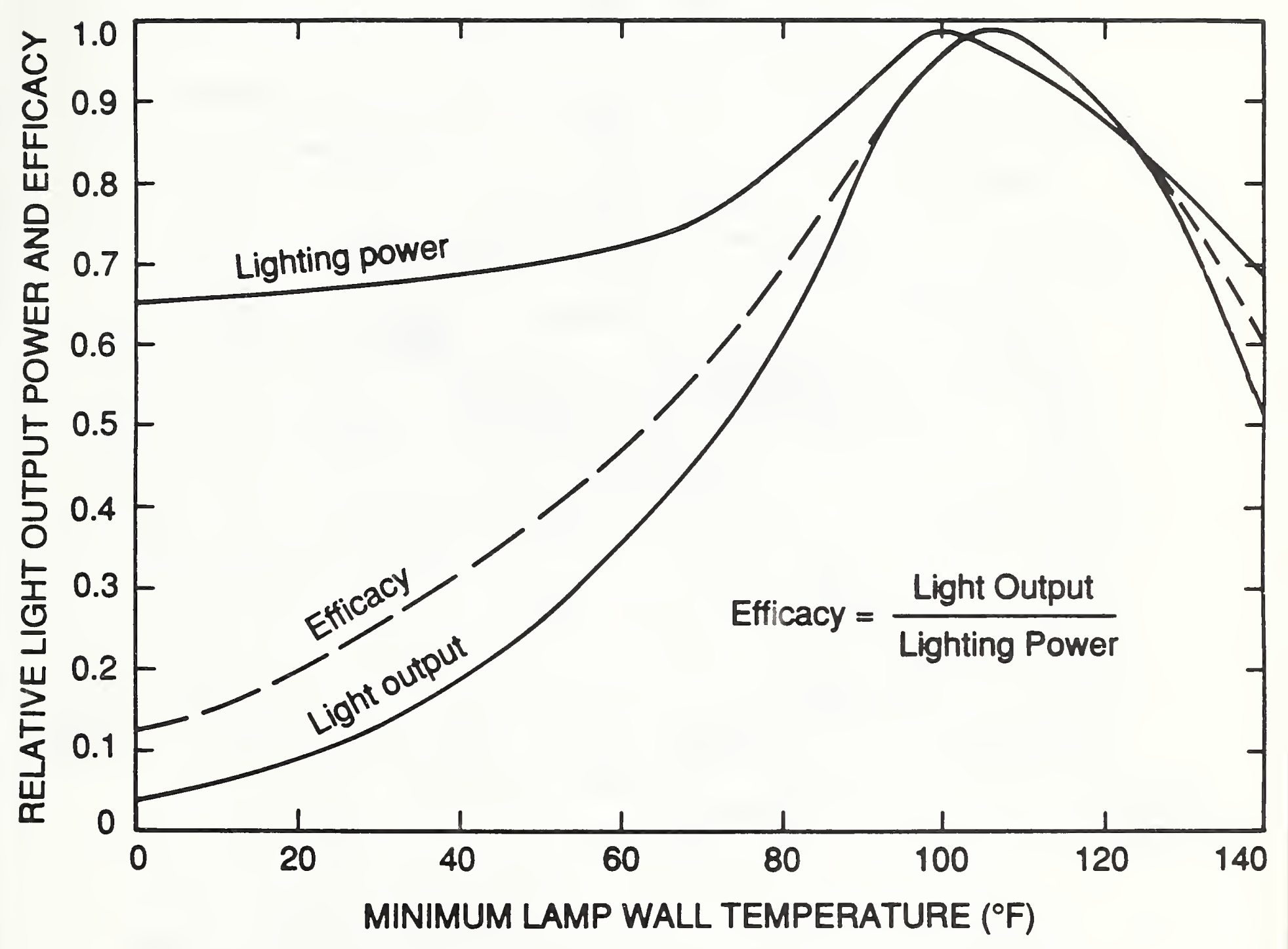

Figure 3. Temperature dependence of a typical fluorescent lamp 


\section{Lighting/HVAC Test Facility}

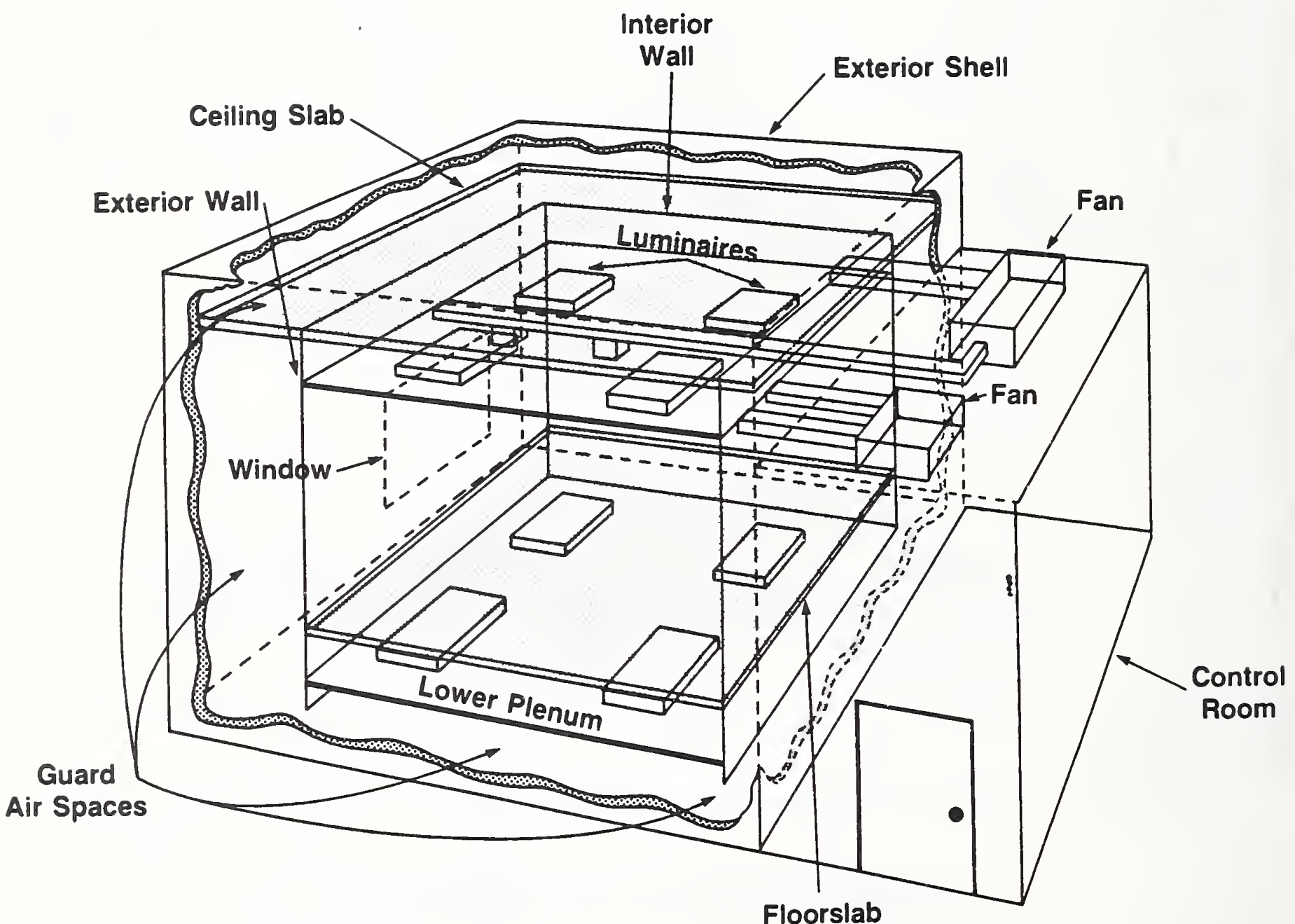

Floorslab

Figure 4. Cut-away schematic of the NIST Lighting/HVAC Interaction Test Facility 


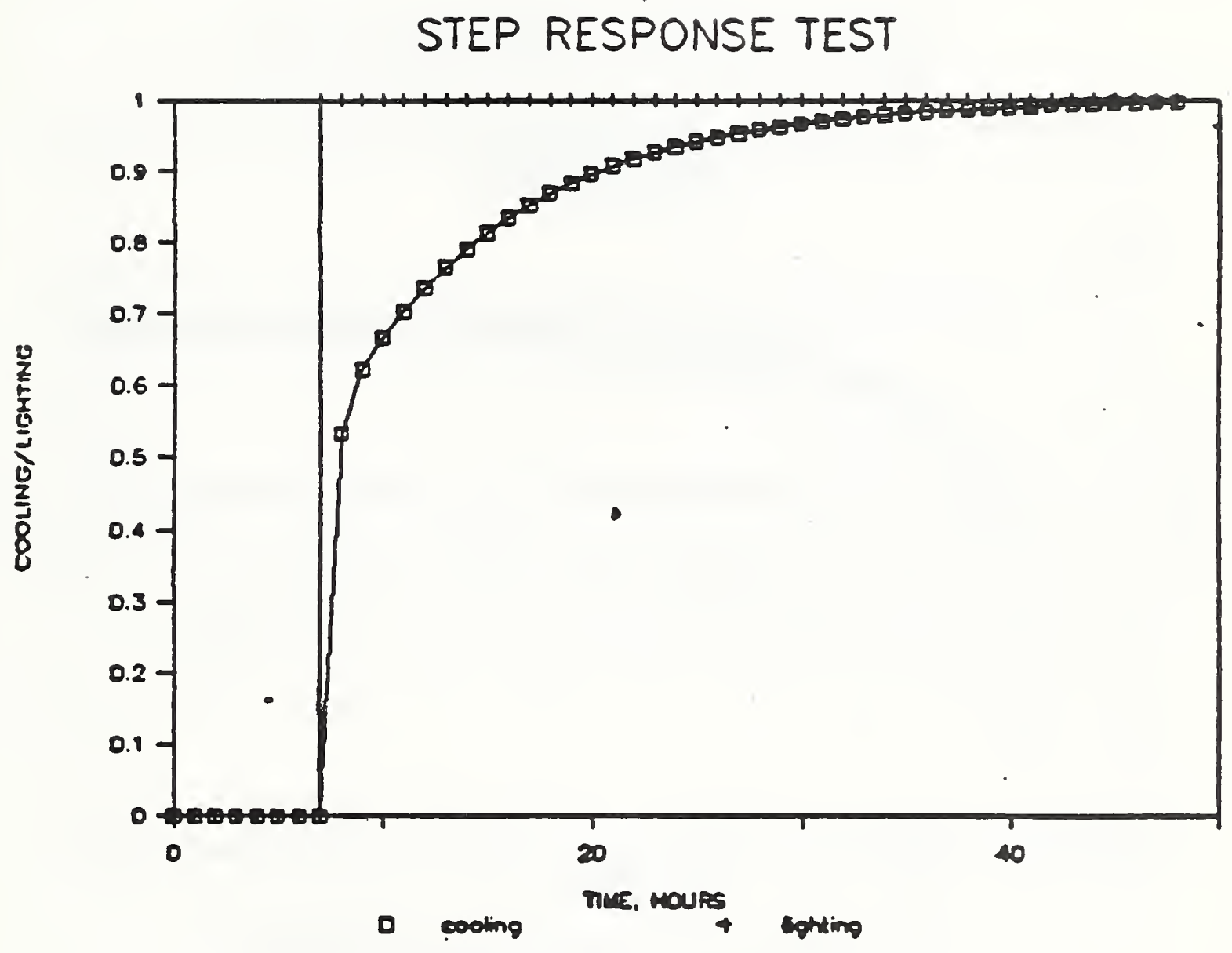

Figure 5. Transient test showing cooling load response due to switching of the lighting system 
ITB, CG, 4X2 ACRL, 40W, CARPET, 75F, 200 CFM

COOLING LOAD. LICHTING POWER (WATTS): ROOM AIR FLOW (CFM)

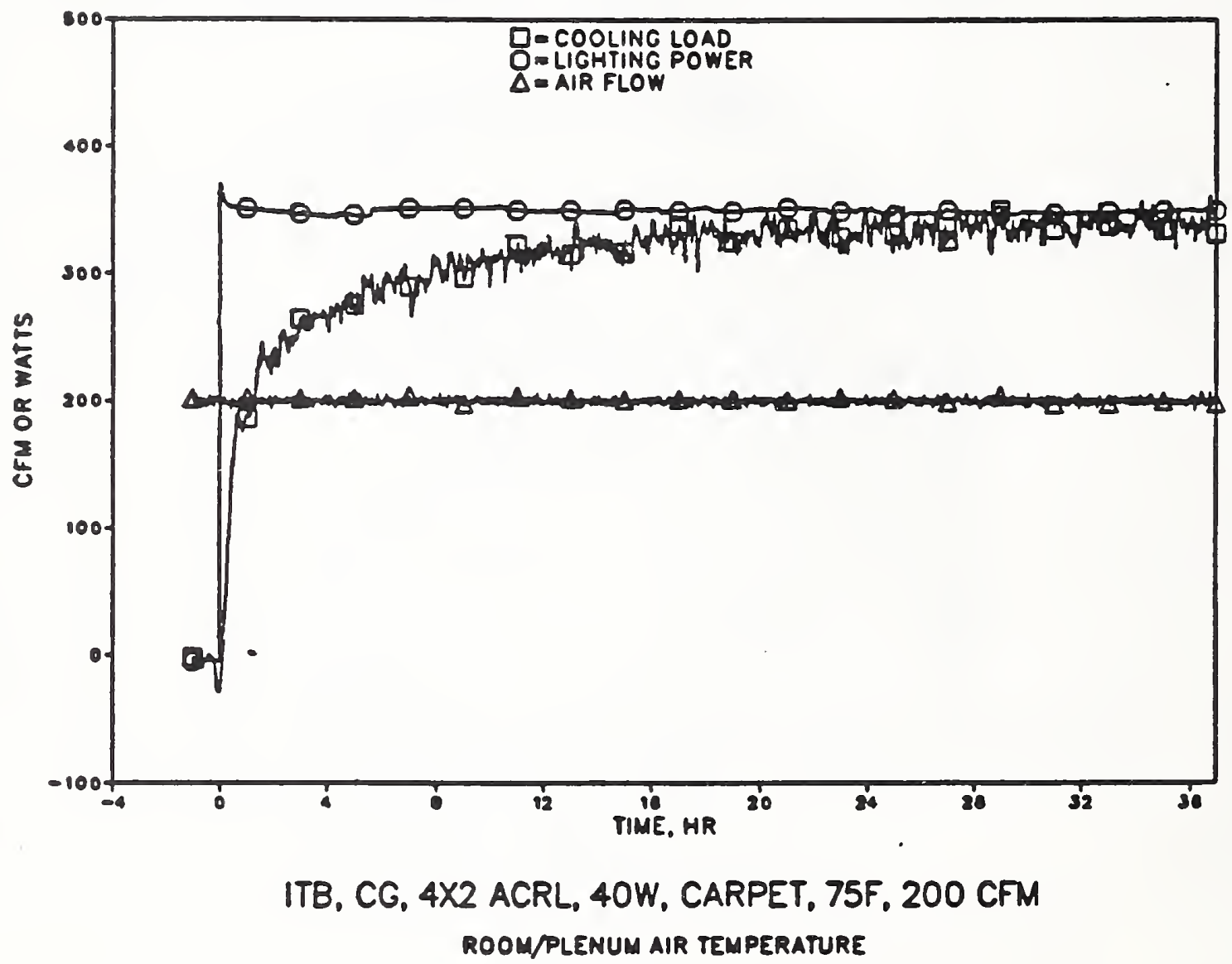

Figure 6. Measured cooling load, lighting power and airflow rate for a trasient lights-on test 


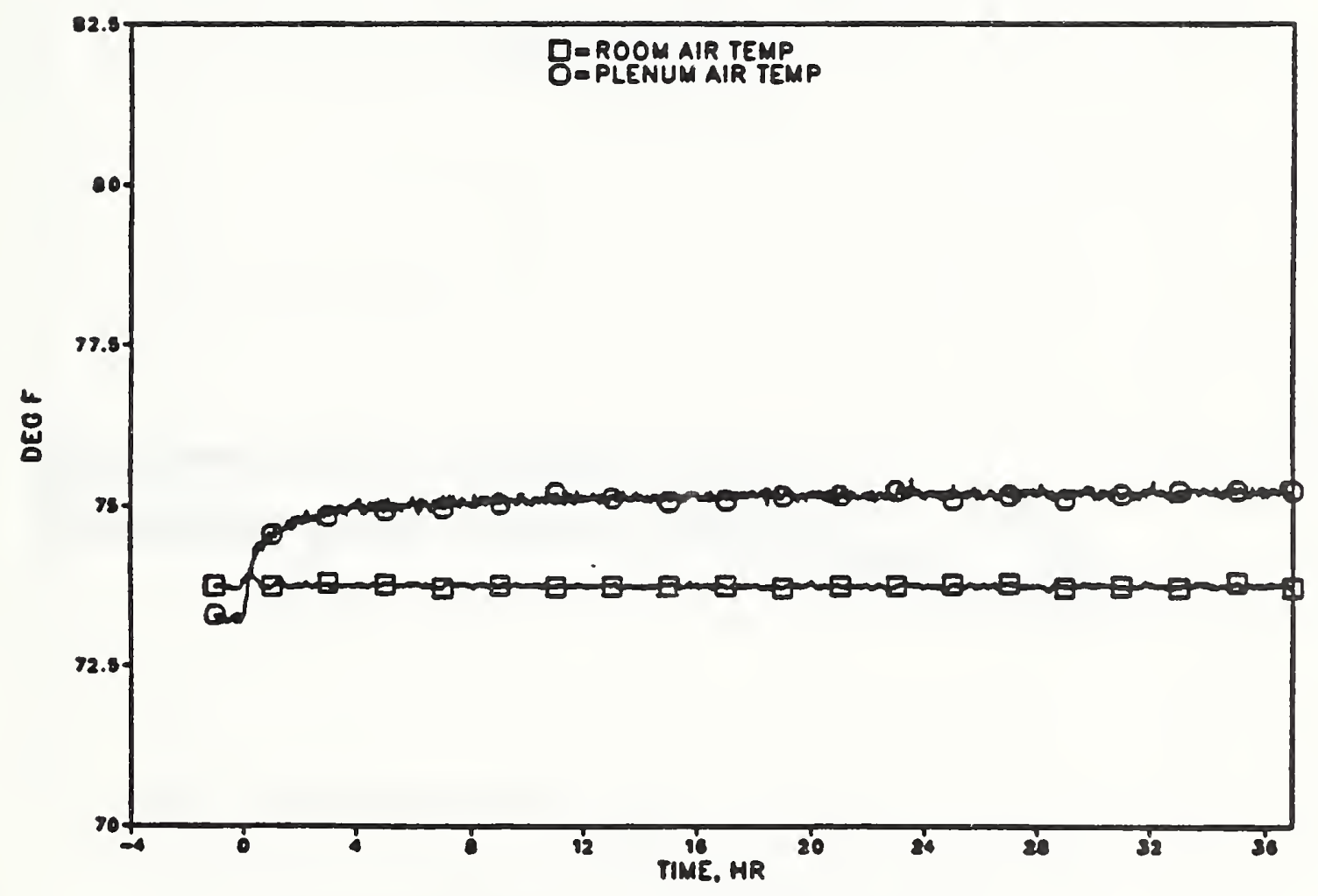

Figure 7. Measured room and plenum air temperatures for a transient lights-on test 
ITB, CG, 4X2 ACRL, 40W, CARPET, 75F, 200 CFM FLOOR/CEILING SURFACE TEMPERATURE

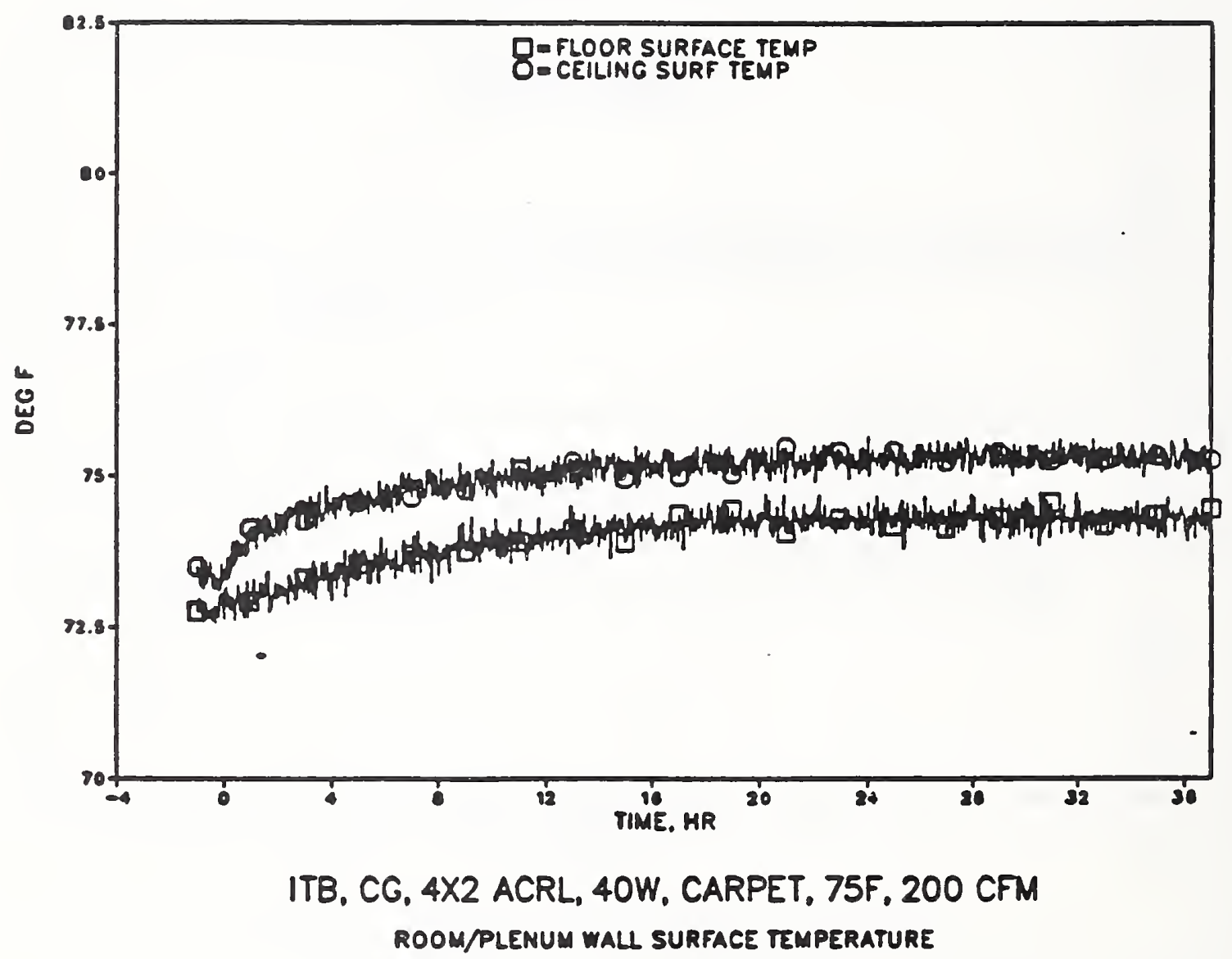

Figure 8. Measured floor and ceiling slab surface temperatures for a transient lights-on test 


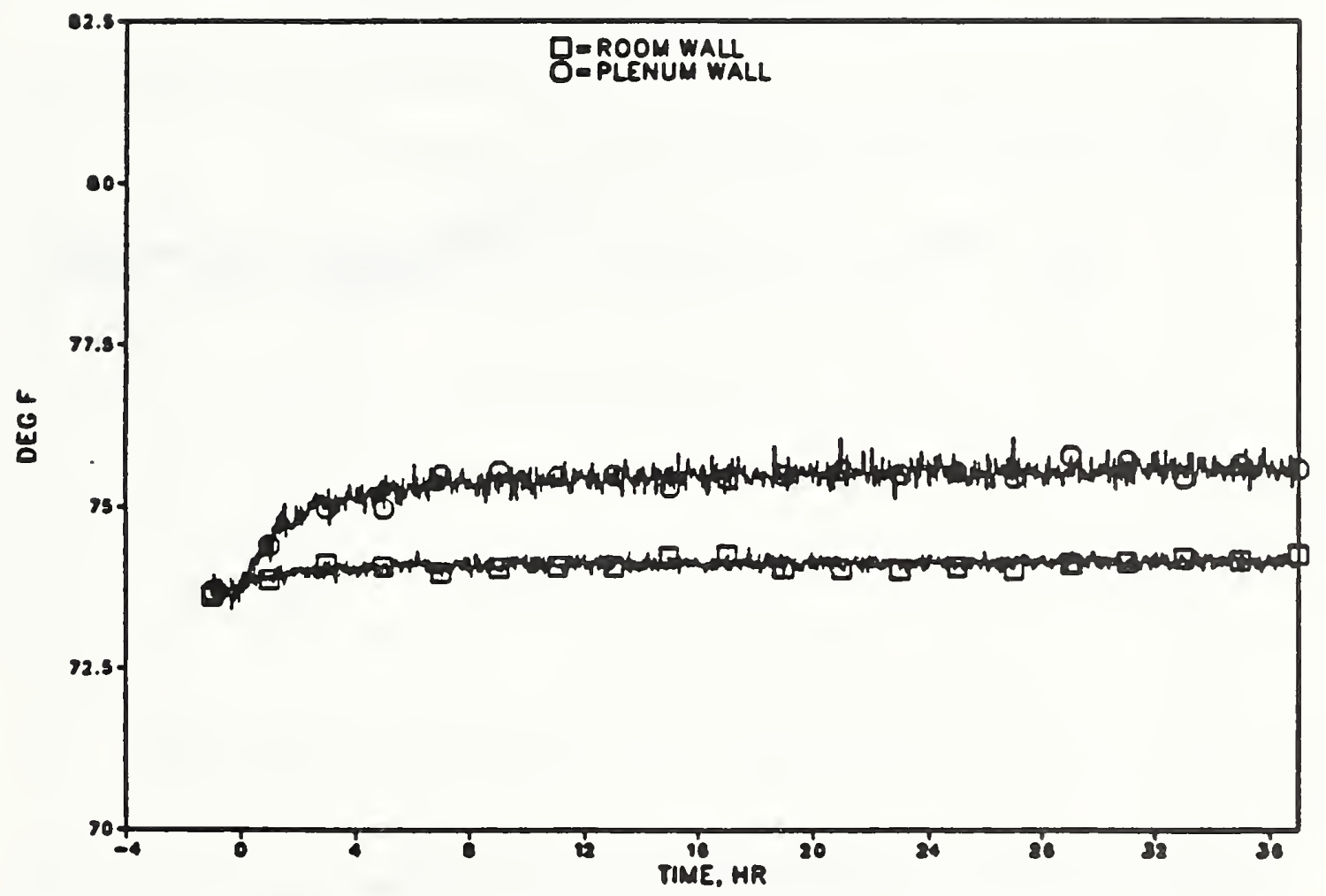

Figure 9. Measured room and plenum wall temperatures for a transient lights-on test 
ITB, CG, 4X2 ACRL, 40W, CARPET, 75F, 200 CFM MINIMUM LAMP WALL SURFACE TEMPERATURE

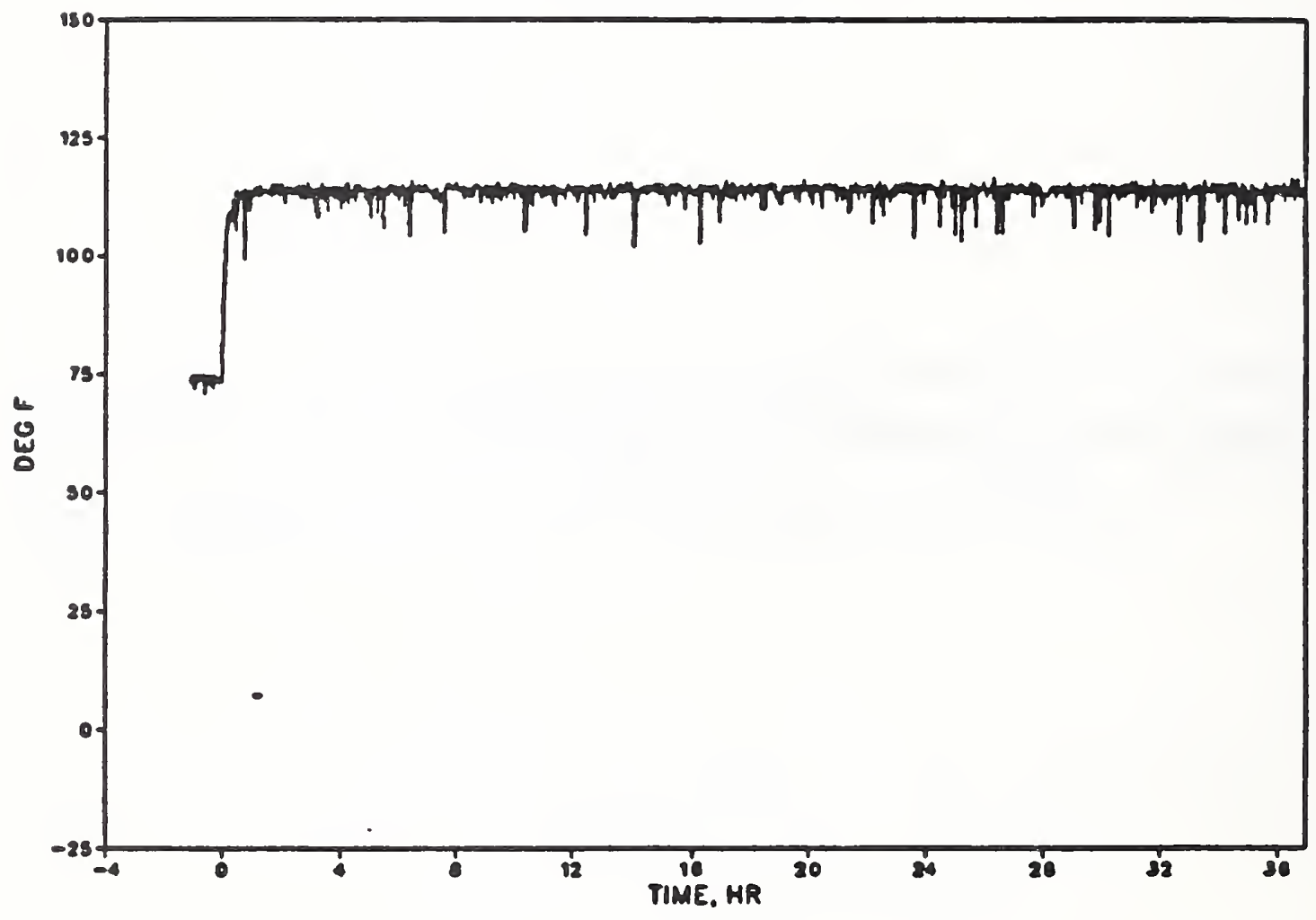

Figure 10. Measured minimum lamp wall temperature for a transient lights-on test 


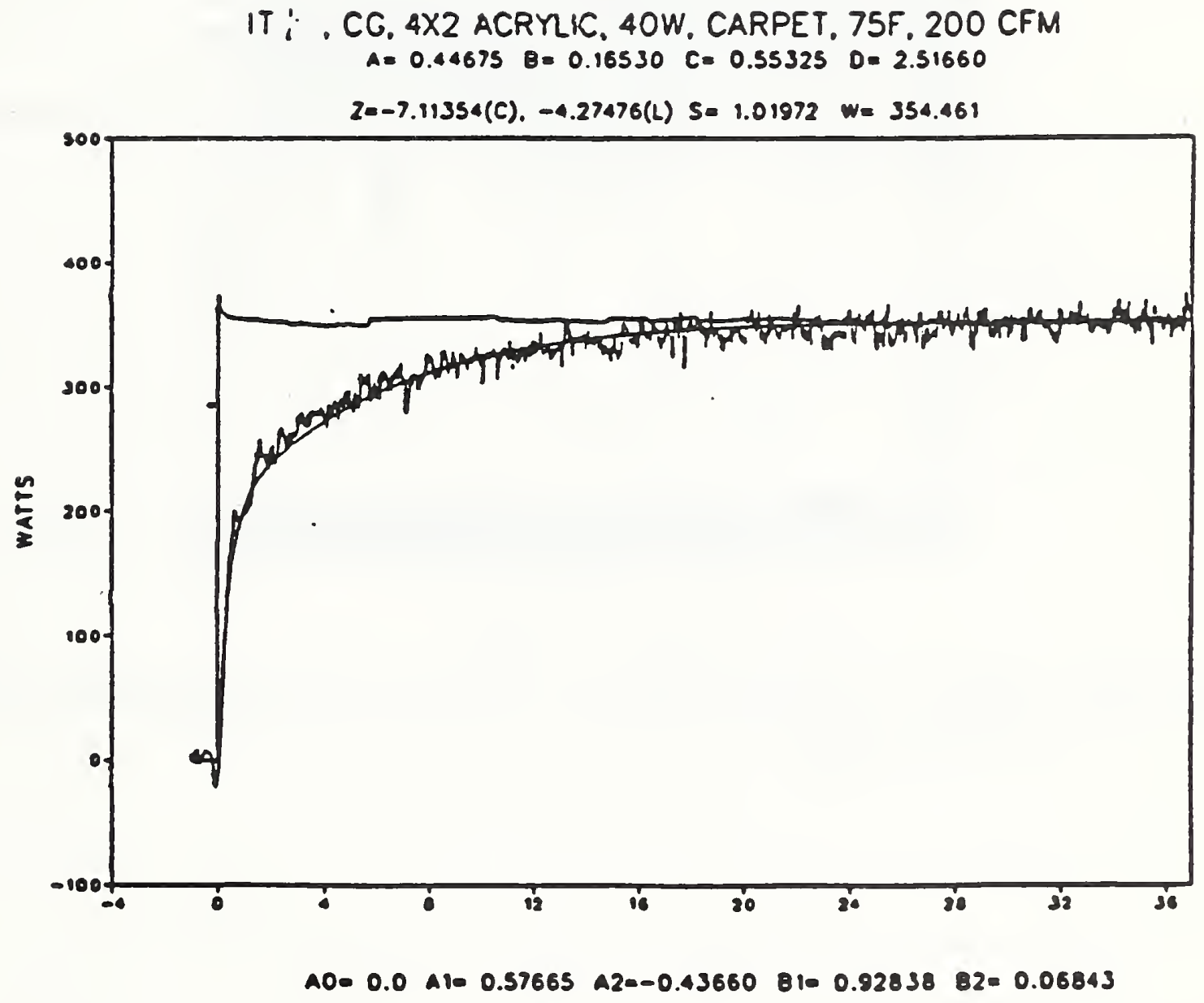

Figure 11. Measured cooling load with experimental curve fit 


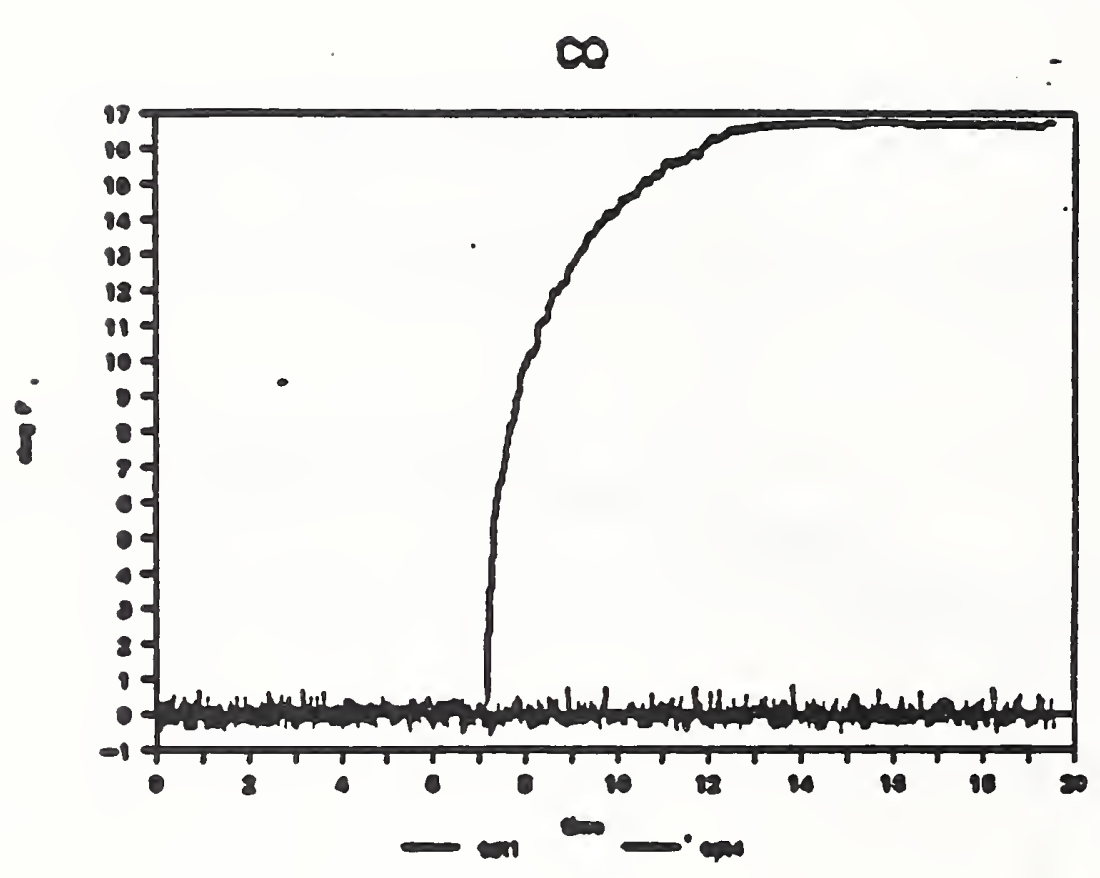

Figure 12. Thermopile readings during a transient test, including wall, slab and air thermopiles 


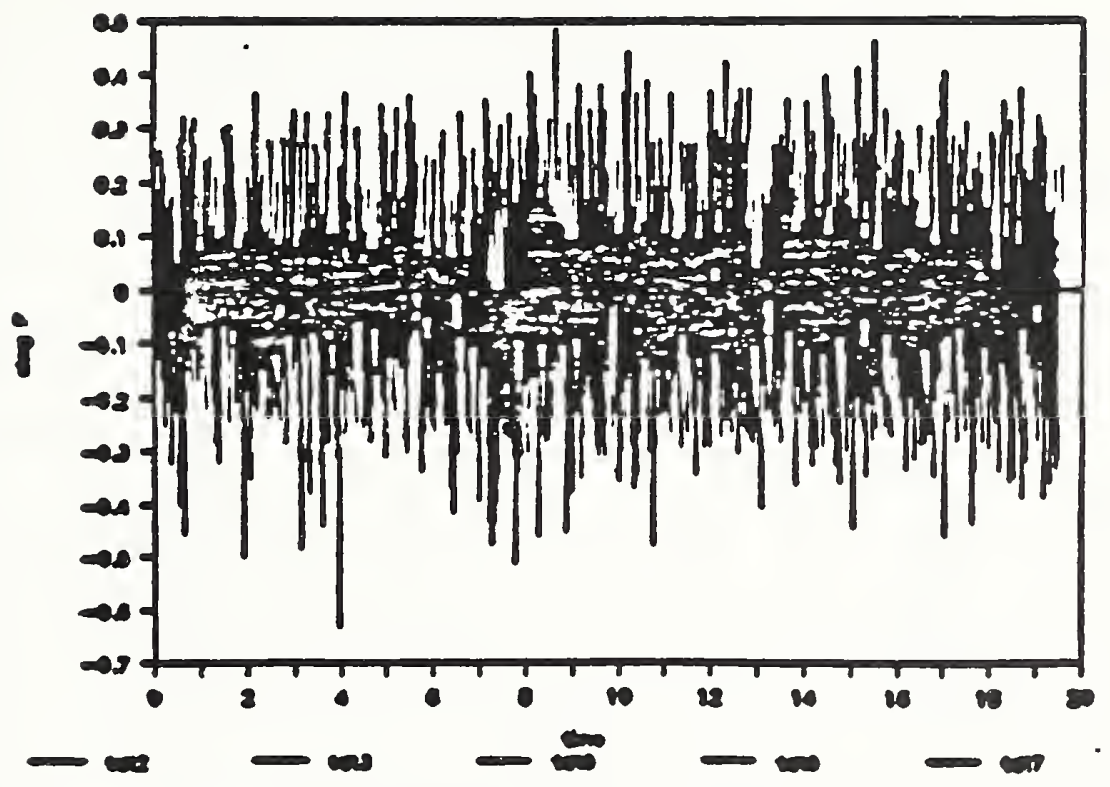

Figure 13. Wall thermopile readings during transient test 
Cooling w'No Excess Heat Gains

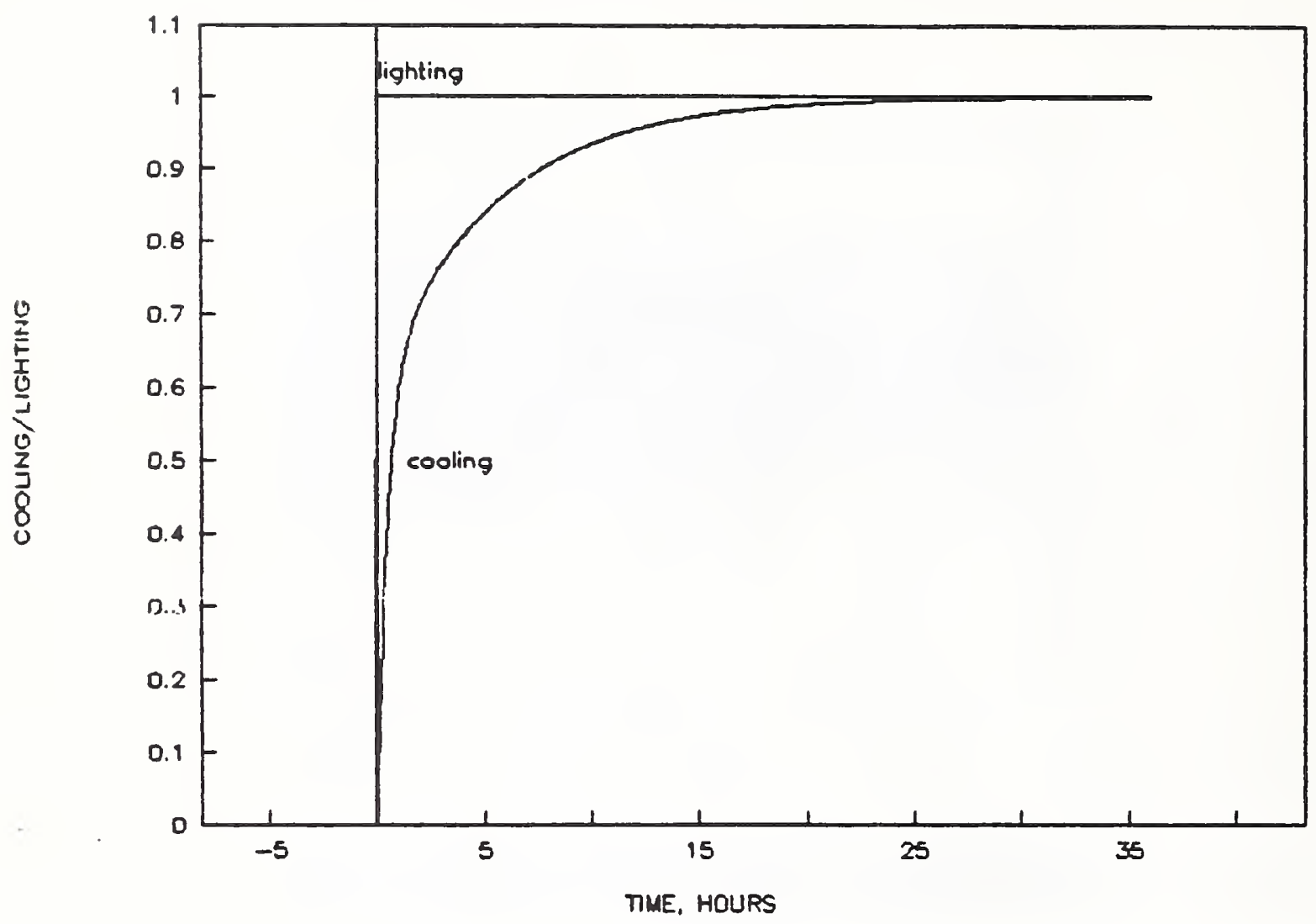

Figure 14. Cooling load profile with no excess heat gains or heat sources 
Cooling w'Constant Excess Heat Gains

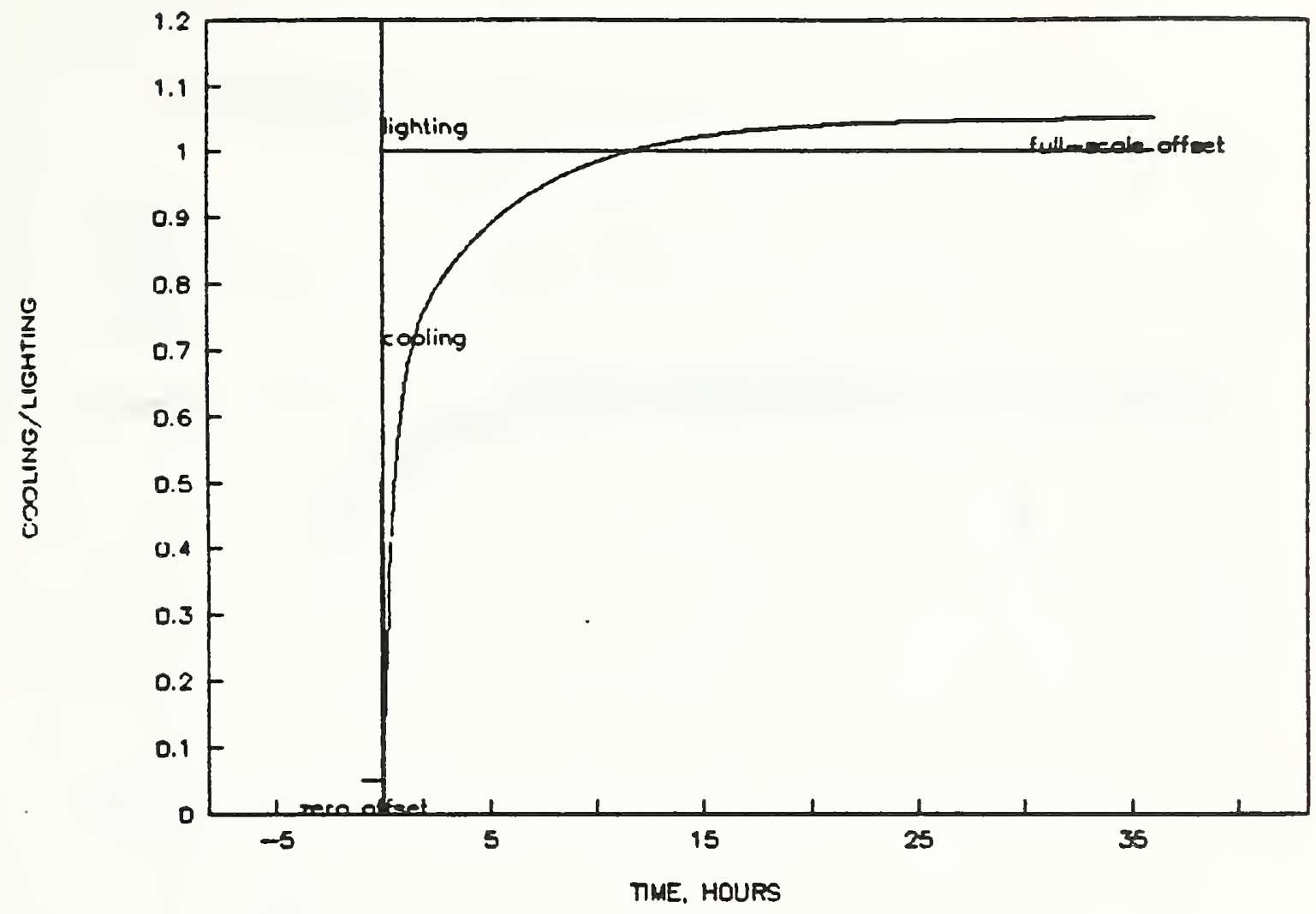

Figure 15. Cooling load profile with constant auxiliary heat source 
Cooling w'Variable Excess Heat Gains

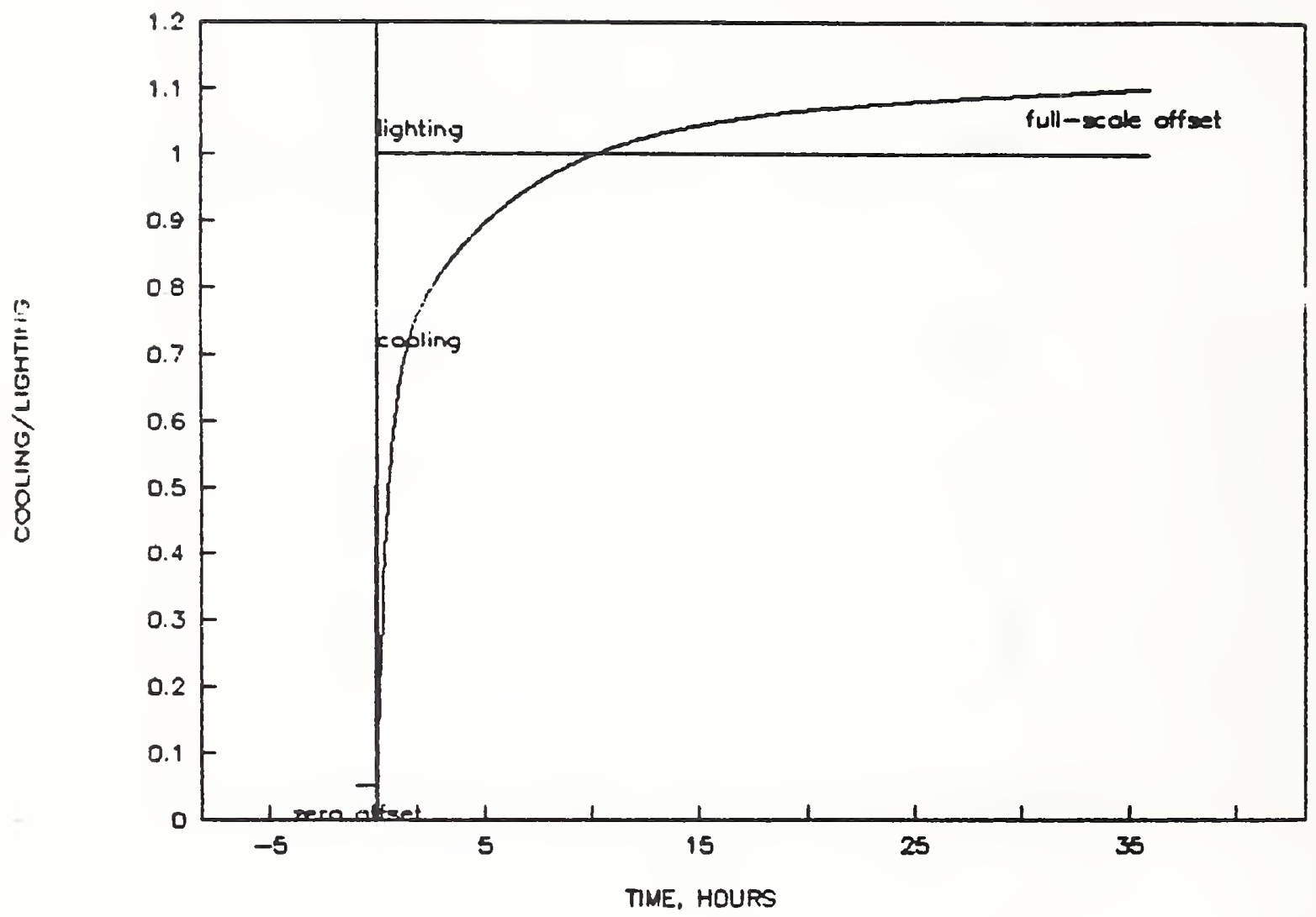

Figure 16. Cooling load profile with variable auxiliary heat source 


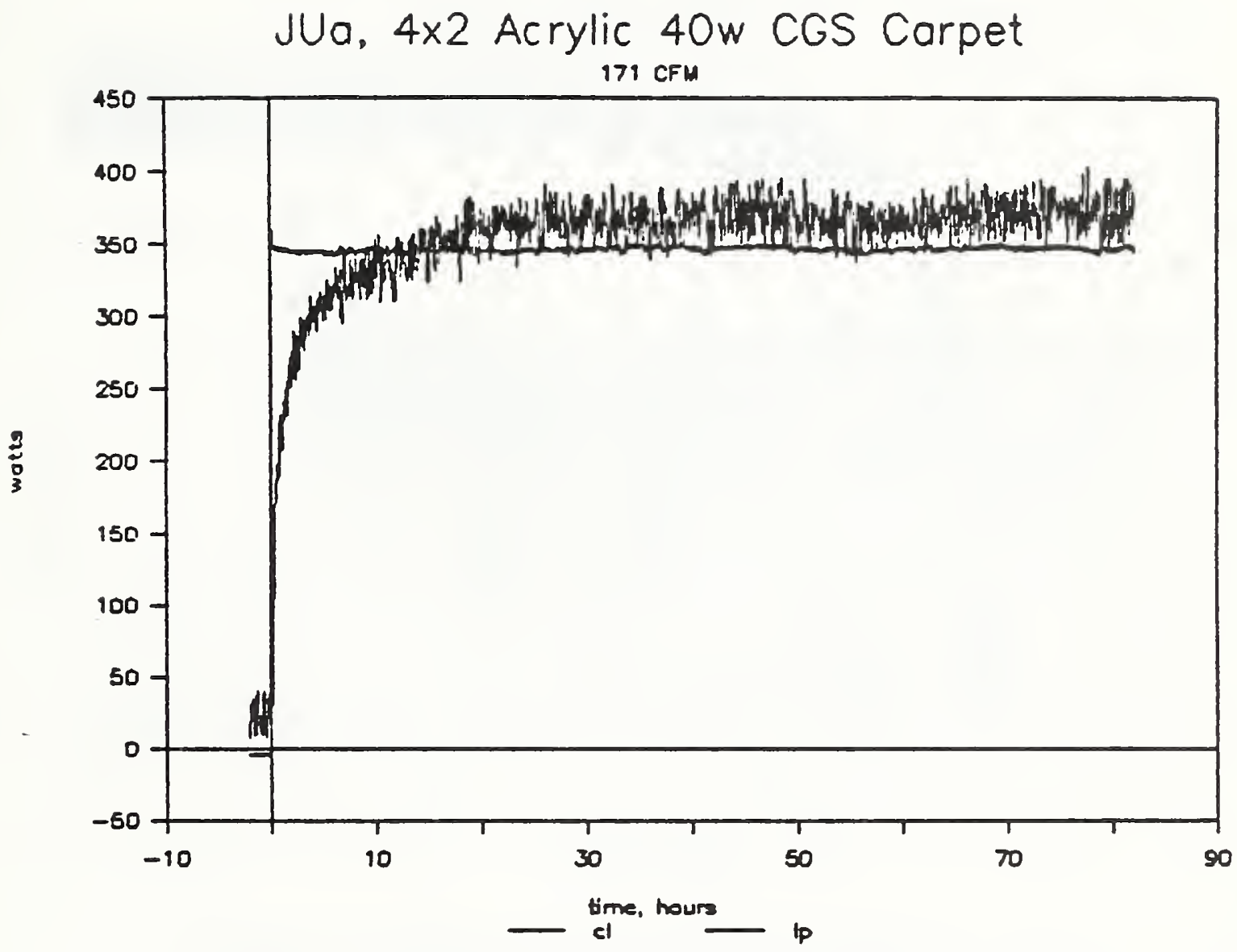

Figure 17. Measured lighting power and cooling load for transient test showing zero and full scale offsets 


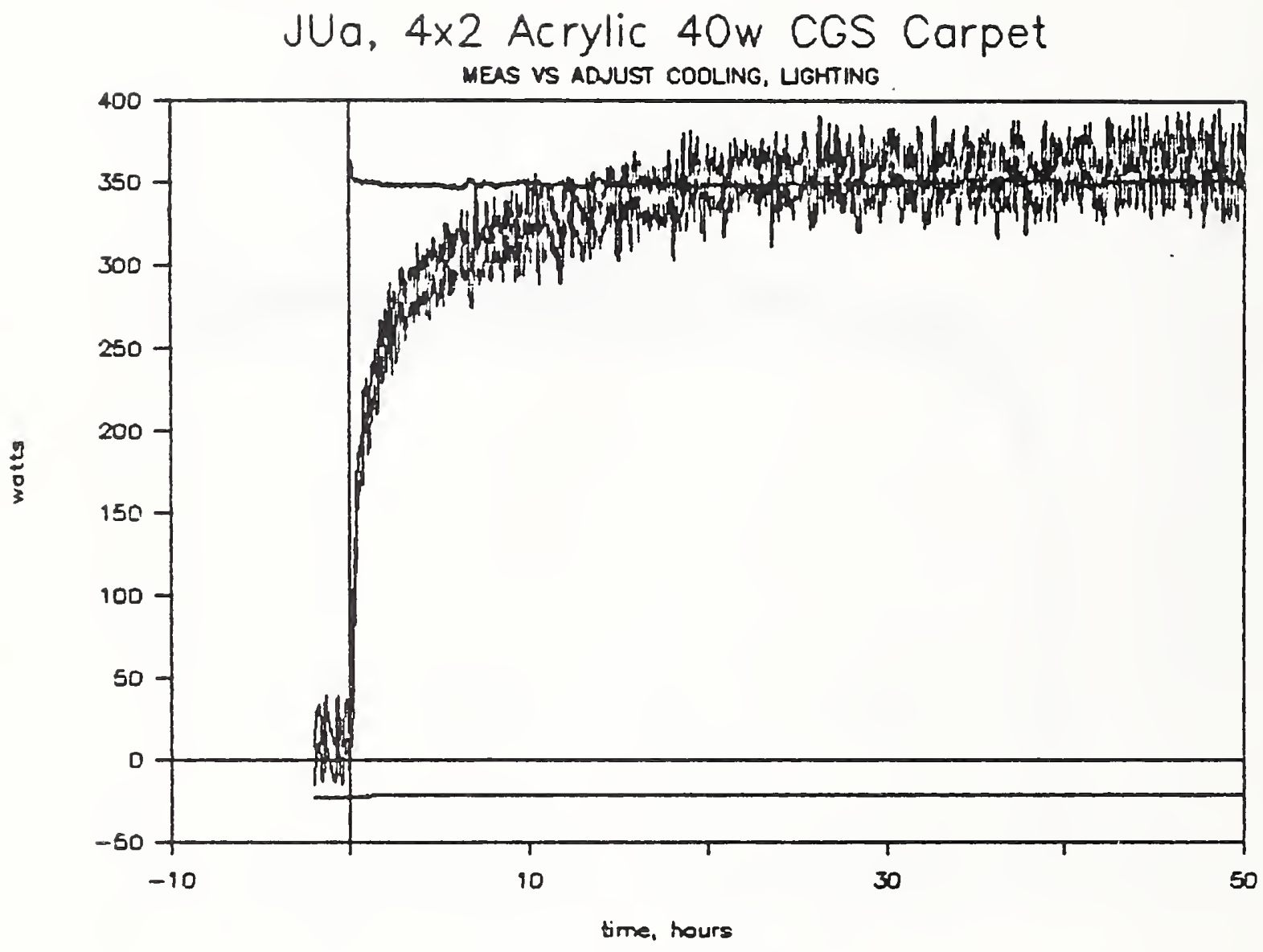

Figure 18. Measured cooling load adjusted for excess heat gains 


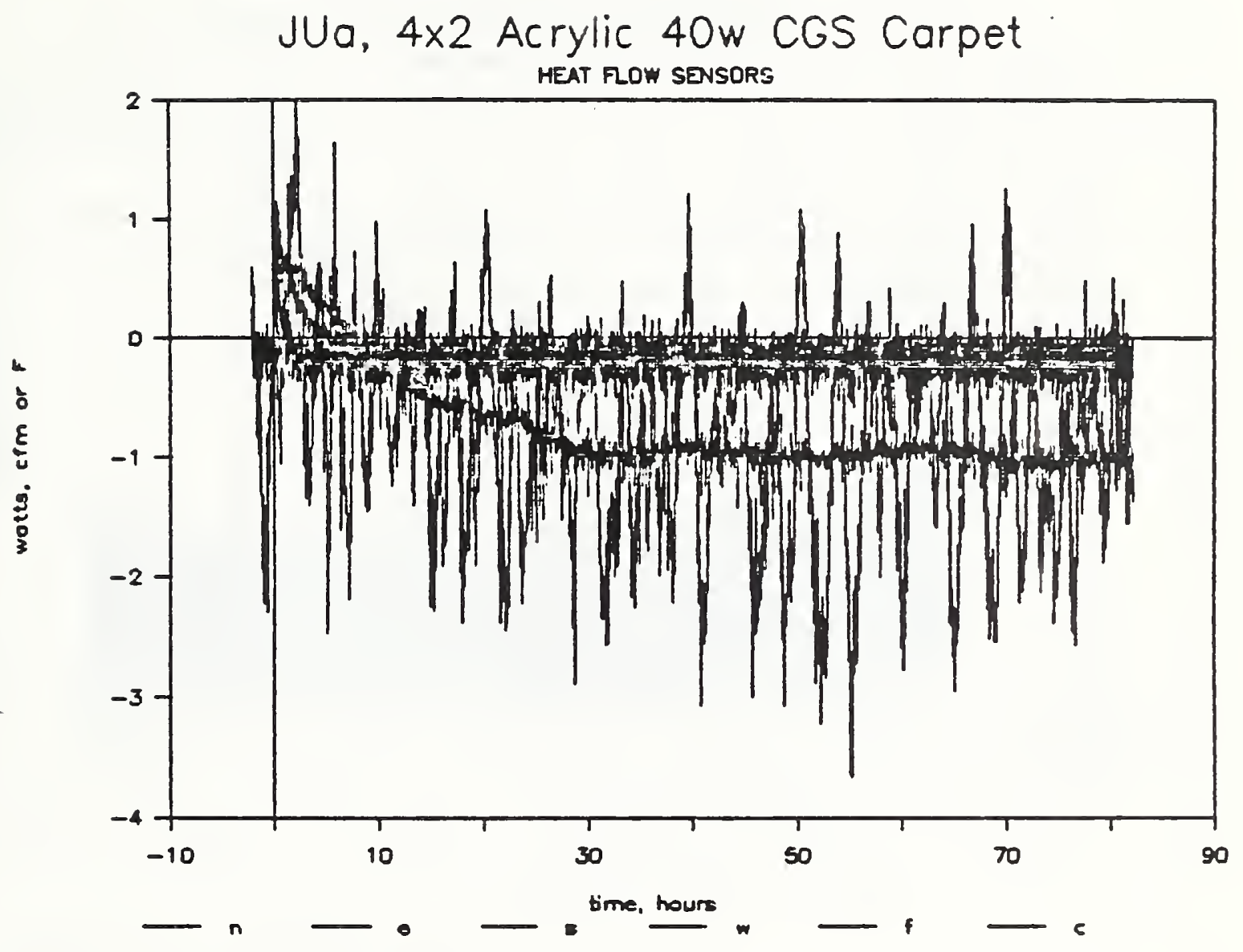

Figure 19. Wall and slab heat flow sensor readings 


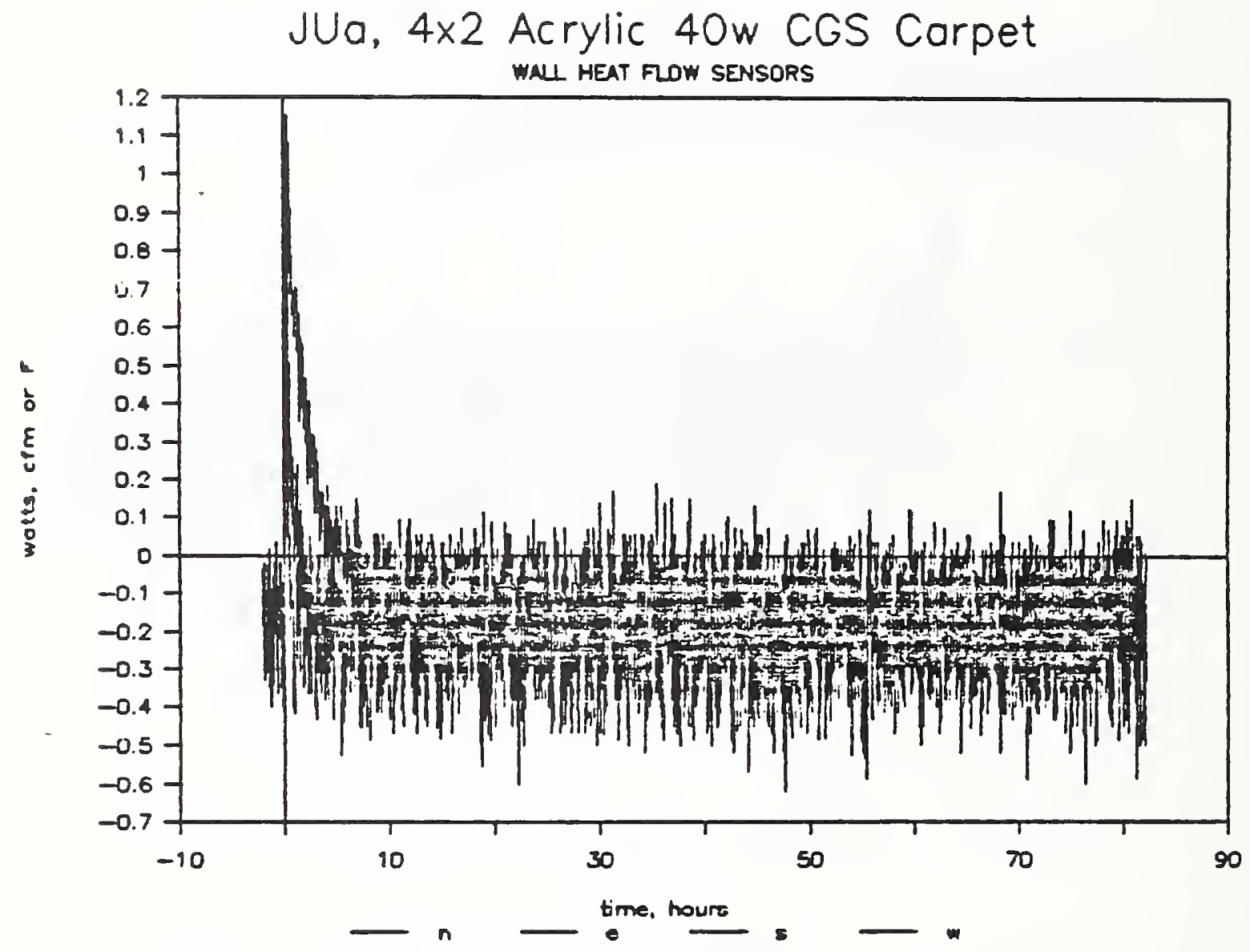

Figure 20. Wall heat flow sensor readings 


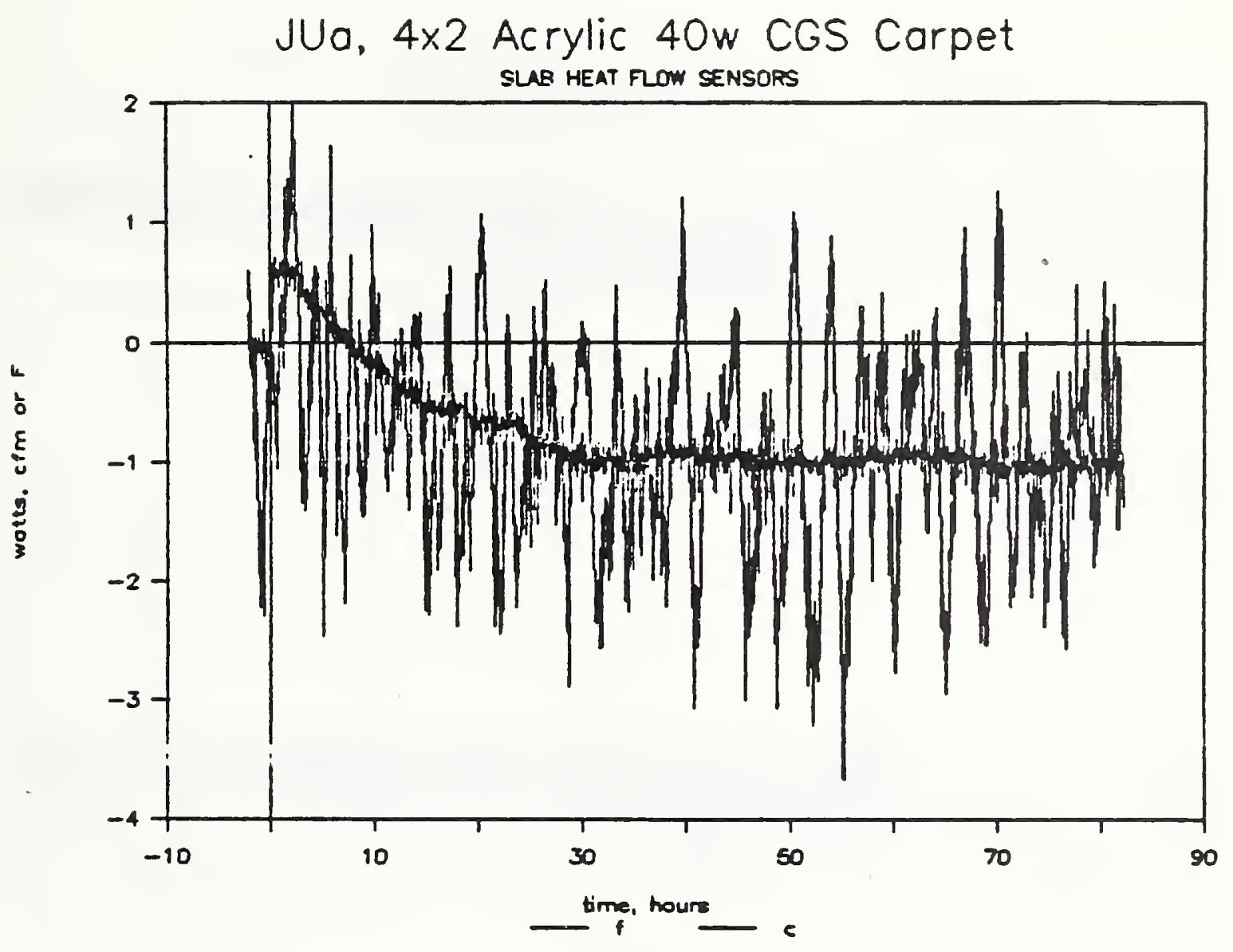

Figure 21. Slab heat flow sensor readings 


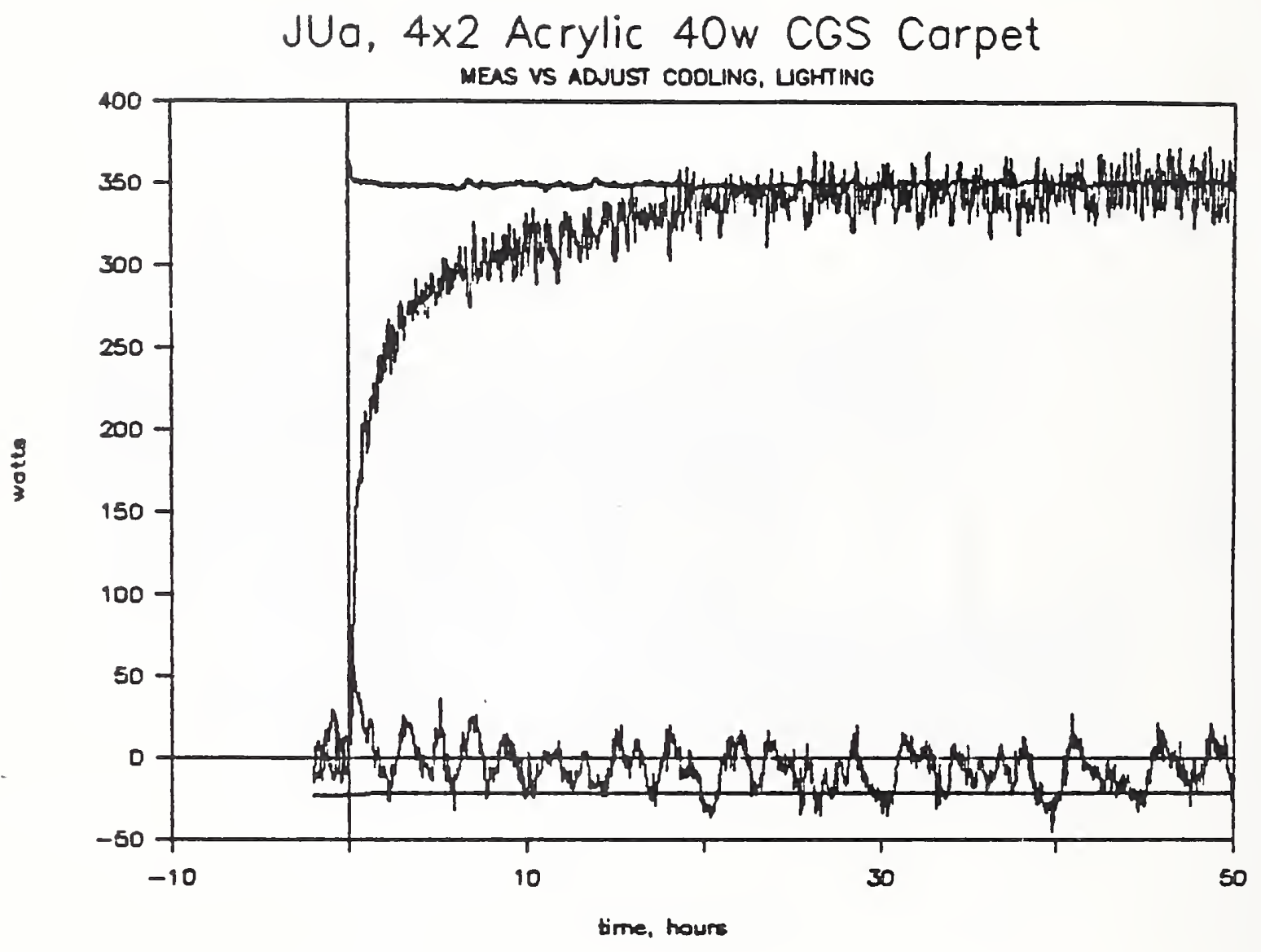

F1gure 22. Excess heat gains based on heat flow sensor readings 


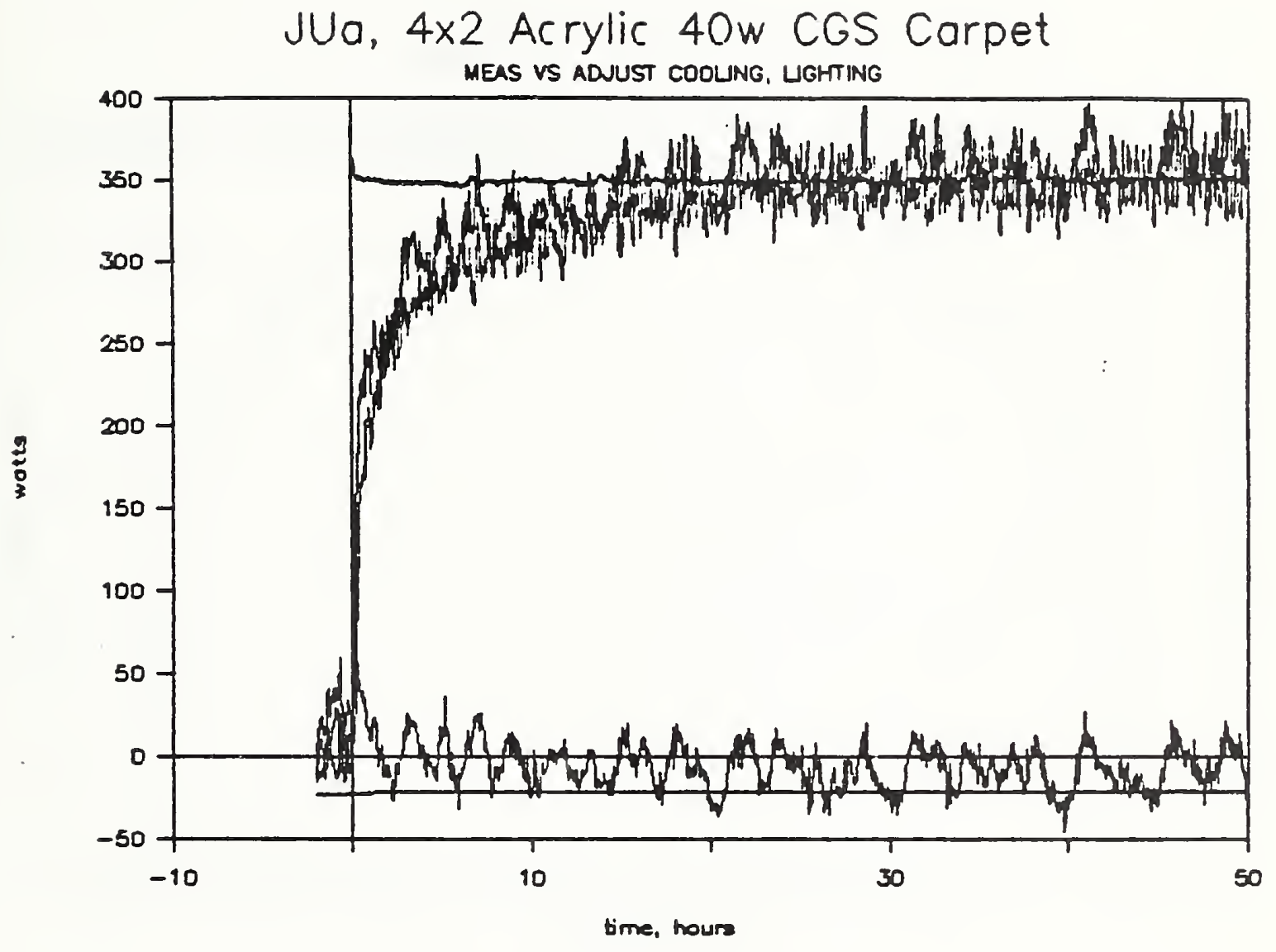

Figure 23. Measured cooling load adjusted using heat flow sensors vs. equilibrium calibration 


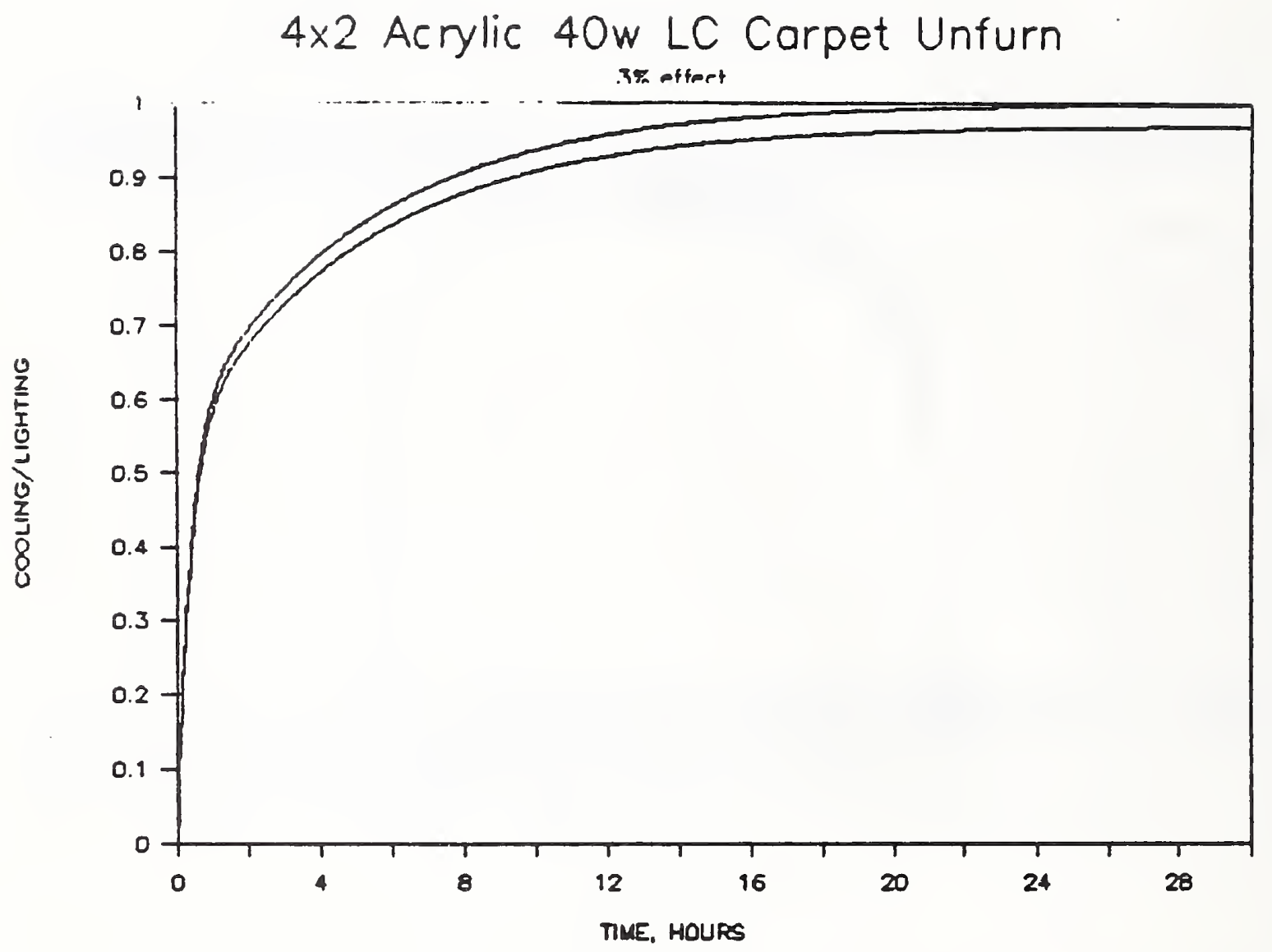

Figure 24. Cooling load profile with 3 percent offset 


\section{3\% EFFECT ON CLF}

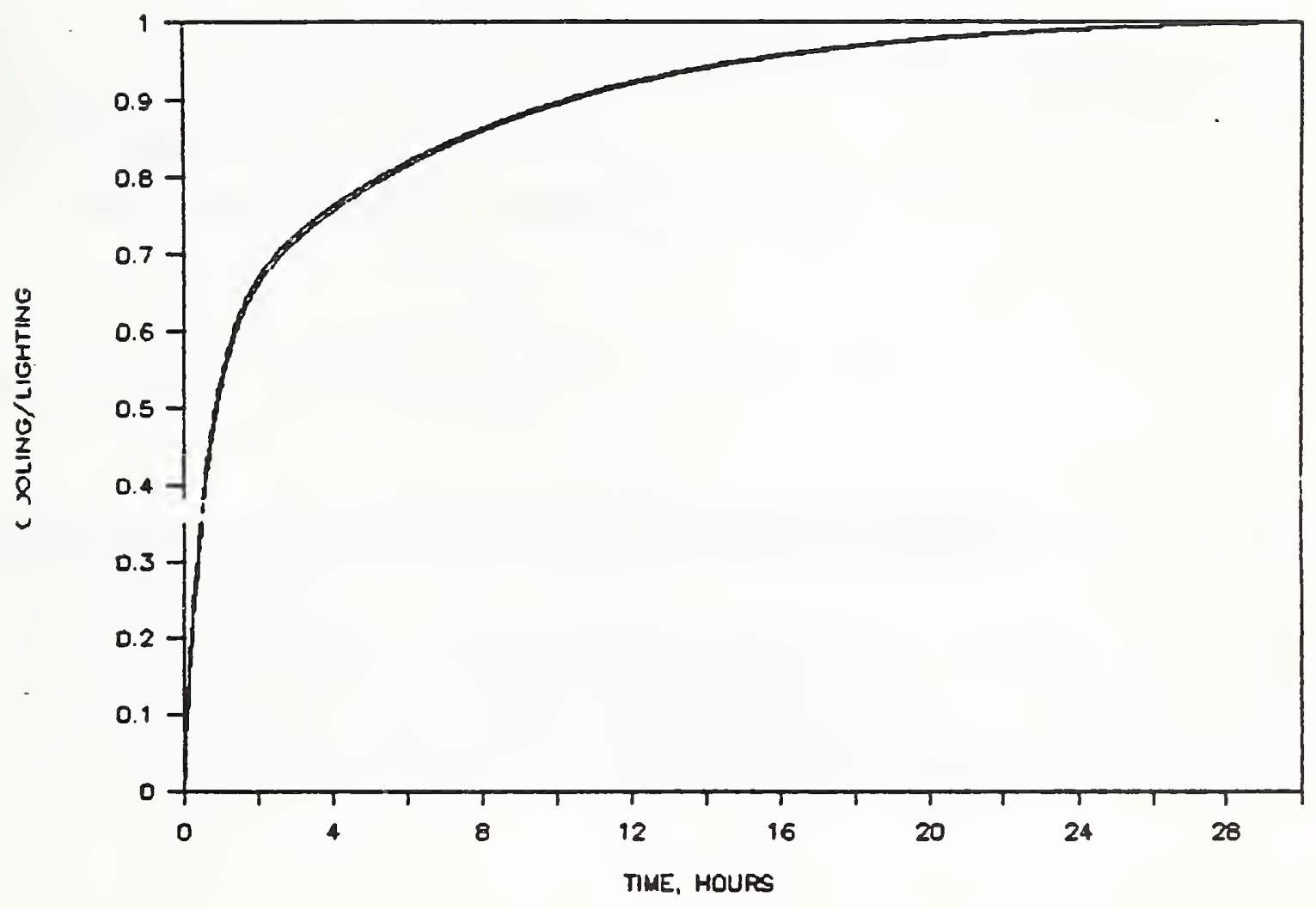

Figure 25. Normalized cooling load profile with 3 percent offset 


\begin{tabular}{|c|c|c|}
\hline \multirow[t]{3}{*}{$\begin{array}{l}\text { NIST-114A } \\
\text { (REV. 3-69) }\end{array}$} & \multirow{3}{*}{$\begin{array}{l}\text { U.S. DEPARTMENT OF COMMERCE } \\
\text { NATIONAL INSTITUTE OF STANDARDS AND TECHNOLOGY } \\
\text { BIBLIOGRAPHIC DATA SHEET }\end{array}$} & $\begin{array}{l}\text { 1. PUBLCATION OR REPORT NUMBEA } \\
\text { NISTIR } 4429\end{array}$ \\
\hline & & 2. PERFORMIMG ORQAMIZATION REPOAT MUMBEF \\
\hline & & $\begin{array}{l}\text { 3. PUBLCATION DATE } \\
\text { MAY } 1991\end{array}$ \\
\hline
\end{tabular}

4. TITLE AND SUBTITLE

Measurement and Evaluation of Lighting/HVAC Interaction

5. AUTHOR(S)

Stephen J. Treado and John W. Bean

6. PERFORMING ORGANIZATION (IF JOINT OR OTHER THAN NIST, SEE INSTRUCTIONS)

U.S. DEPARTMENT OF COMMERCE

MATIONAL INSTITUTE OF STANDARDS AND TECHNOLOGY

GAITHERSBURG, MD 20899

7. CONTRACT/ORANT NUMBER

8. TYPE OF REPORT AND PERIOD COVEAED

9. SPONSORING ORGANIZATION NAME AND COMPLETE ADDRESS (STREET, CITY, STATE, ZIP)

10. SUPPLEMENTARY NOTES

DOCUMENT DESCRIBES A COMPUTER PROGRAM; SF-185, FIPS SOFTWARE SUMMARY, IS ATTACHED.

11. ABSTRACT (A 200-WORD OR LESS FACTUAL SUMMARY OF MOST SIGNIFICANT IMFORMATION. IF DOCUMENT INCLUDES A SIONIFICANT BIBLUOQRAPHY OR LTERATURE SURVEY, MENTION IT HERE.)

The interaction of building lighting and HVAC systems and the effects on cooling load and lighting system performance are being evaluated using a full-scale test facility at the National Institute of Standards and Technology (NIST). The test facility and measurement methodology are described, along with sample test data and performance evaluation results. The implications of measurement uncertainty on results are discussed.

12. KEY WORDS (6 TO 12 ENTAIES; ALPHABETICAL ORDER; CAPITALZE ONLY PROPER MAMES; AND SEPARATE KEY WORDS BY SEMICOLONS) airflow, cooling, energy, lighting, load calculation, ventilation

13. AVAILABIUTY

UNUMTrED

FOR OFFICLL DISTRIBUTION. DO NOT RELEASE TO MATIONAL TECHNICAL IMFOAMATION SERVICE (NTIS).

ORDER FROM SUPERINTENDENT OF DOCUMENTS, U.S. GOVERMMENT PRINTINO OFFICE, WASHINOTON, DC 20402.

$\mathrm{x}$

ORDER FROM MATIONAL TECHNICAL INFORMATION SEAVCE (NTIS), SPRINOFIED, VA 22161.
14. MUMBER OF PRINTED PAGES

$$
54
$$

15. PRICE

$\mathrm{A} 04$ 


